\title{
Measuring Occupational Mismatch: Overeducation and Overskill in Europe-Evidence from PIAAC
}

\author{
Sara Flisi ${ }^{1}$ - Valentina Goglio ${ }^{1}$ Elena Claudia Meroni ${ }^{1} \cdot$ \\ Margarida Rodrigues ${ }^{2} \cdot$ Esperanza Vera-Toscano $^{1}$
}

Accepted: 2 March 2016/Published online: 9 March 2016

(C) The Author(s) 2016. This article is published with open access at Springerlink.com

\begin{abstract}
Occupational mismatch has been a hot topic in the economics literature in recent decades; however, no consensus has been reached on how to conceptualise and measure this phenomenon. We explore the unique opportunity offered by the PIAAC survey to measure occupational mismatch at the individual level based on both education- (overeducation) and skill-based (overskilling) variables by using both objective and subjective measures. For this purpose, we use data on 17 European countries and compute up to 20 different indicators of occupational mismatch. We find that the conceptualisation and measurement of occupational mismatch are indeed important and that education and skill mismatch do not measure the same phenomenon. In fact, only a small percentage of mismatched individuals are mismatched with respect to both education and skill, whereas the majority are mismatched with respect to either education or skill only. At the country level, we find a negative correlation between the incidence of education and skill mismatch, which has important implications for policies aiming to address this labour market inefficiency.
\end{abstract}

Keywords Occupational mismatch · Overeducation · Overskilling · PIAAC

Esperanza Vera-Toscano

esperanza.vera-toscano@jrc.ec.europa.eu

Sara Flisi

sara.flisi@jrc.ec.europa.eu

Valentina Goglio

valentina.goglio@jrc.ec.europa.eu

Elena Claudia Meroni

elena.meroni@jrc.ec.europa.eu

Margarida Rodrigues

Margarida.Rodrigues@iab.de

1 DDG.01 - Econometrics and Applied Statistics Unit, European Commission - Joint Research Centre, Via E. Fermi 2749, 21027 Ispra, VA, Italy

2 Institute for Employment Research (IAB), German Federal Employment Agency (BA), Regensburger Strasse 104, 90478 Nuremberg, Germany 


\section{Introduction}

In the last two to three decades, socio-economic changes such as increased global competition, skill-biased technological adjustments, an increased work force education level, and an ageing population have created a labour market situation where finding the right people for the right jobs is often difficult. This labour market situation leads to the phenomenon of occupational mismatch, defined as a discrepancy between workers' skills and competencies and those required by the job. Although some theories indicate that occupational mismatch is a temporary or individual phenomenon, empirical evidence shows that occupational mismatch in Europe is pervasive (Cedefop 2010), widespread, and persistent, suggesting that the phenomenon may result from the labour market structure (Brynin 2002). ${ }^{1}$ Better matching between workers' potential and actual jobs is nevertheless essential to combat unemployment and to boost the competitiveness of European countries. Further, good job matching may improve individual welfare and have positive effects on the productivity and growth of the economy. ${ }^{2}$

To overcome this challenge, the first and principal concern is to find an appropriate measure of individual occupational mismatch. Education mismatch is the most common way to conceptualise occupational mismatch, whereby educational attainment is used as the variable to summarise an individual's competencies. However, even if educational attainment is a reasonable candidate to serve as a proxy for individuals' skills and competencies, there is no one-to-one correspondence between one's educational attainment and one's skills and competencies. In fact, as argued by the OECD, 'more education does not automatically translate into better skills'. Individual skills are a broader and more dynamic feature, as they are supposed to increase with working experience and job training, according to human capital theory (see Becker 1976). Moreover, the actual level of skills possessed by individuals of the same education level can vary across different age cohorts because of changes in the educational system and the deteriorating effect of the ageing process. Thus, measuring adults' skills rather than educational attainment is considered a superior and more reliable approach to quantifying an individual's actual competencies at a specific point in time.

Yet, using skills to conceptualise and measure occupational mismatch has been overlooked until relatively recently because of the impossibility of validly and reliably measuring skills. Beginning in the 1990s, the release of surveys such as the International Adult Literacy Survey (IALS), the Adult Literacy and Lifeskills Survey (ALLS), and most of all, the recent Survey on Adult Skills (PIAAC) ${ }^{3}$ paved the way for an analysis of skill mismatch. In fact, these surveys, in addition to measuring traditional educational attainment variables, assess skills in domains such as literacy, numeracy, and problem solving in technology-rich environments.

Given the undeniable need to make thoughtful progress on the conceptualisation and measurement of occupational mismatch for effective policy making, we exploit the

\footnotetext{
1 A review by Groot and Maassen van den Brink (2000) of 20 years of research on overeducation in Europe and USA further suggests that the rate of overeducation has not significantly changed over the period from the 1970 s to the 1990 s.

${ }^{2}$ For further information on the consequences of occupational mismatch, see Brynin (2002), Ortiz (2010), Quintini (2011), and Dolado et al. (2002), among others.

3 The Survey of Adult Skills is an international survey conducted as part of the Programme for the International Assessment of Adult Competencies (PIAAC). For the sake of simplicity, in this paper, we use the acronym PIAAC to refer to the survey.
} 
exceptional opportunity offered by PIAAC data to measure occupational mismatch ${ }^{4}$ at the individual level using both education- and skill-based variables. Thus, the main objective of this paper is to examine whether overeducation and overskilling measure the same or different phenomena of occupational mismatch and how this (these) phenomenon (phenomena) varies across European countries. To accomplish this aim, we proceed in two stages. First, we compute several mismatch indicators measuring both educational and skill mismatch and applying both objective and subjective approaches. Because it is unclear how many latent variables are captured by the 20 indicators computed, we conduct a principal component analysis (PCA). The results show that 3 latent components underlie the different indicators computed, one capturing educational mismatch and two capturing skill mismatch. This finding suggests that education and skill mismatch are two distinct phenomena, which has important policy implications, as discussed below. Second, using original education and skill mismatch variables from the 3 components identified through the PCA exercise, we investigate the extent to which education mismatch and skill mismatch vary and eventually overlap at the country level in Europe. We find that there is a low extent of overlap between education and skill mismatch and that there is a strong negative correlation between the percentages of the population only educational mismatched and that only skill mismatched. This result supports the importance of conceptualisation and operationalisation of occupational mismatch and suggests that there is not a one-size-fits-all approach to measuring and addressing this type of inefficiency in the labour market.

This paper adds to the previous literature in two ways. First, to our knowledge, this is the first study to compare such a large number of measures of overeducation and overskilling. A few other studies have conducted a similar line of investigation by comparing different measures with a common dataset (Verhaest and Omey 2006; Allen and van der Velden 2001; Allen and de Weert 2007; Green and McIntosh 2007 and Mavromaras et al. $2007 \mathrm{a}, \mathrm{b})$. Our conclusions corroborate and extend these findings by providing an analysis on a much broader sample (i.e., one not limited to graduates), with a wider set of mismatch indicators, and for 17 European countries. Moreover, this research reflects the limitations of using a single definition of occupational mismatch across a heterogeneous set of countries. Second, we contribute to the literature by providing an analysis of the overlap between education mismatch and skill mismatch across countries. We link the strong negative correlation identified between education mismatch and skill mismatch to the role and functioning of the educational systems.

The paper is organised as follows. The next section provides a literature review of education and skill mismatch and the indicators used to measure each phenomenon. After providing an overview of data from the PIAAC's Survey of Adult Skills, in Sect. 3, we replicate a number of indicators of upward occupational mismatch by using both education- and skill-based variables, and we perform a PCA to identify the common latent dimensions that some of the mismatch measures may share. In Sect. 4, using original education and skill mismatch indicators, we aim to elucidate the extent of overlapping

\footnotetext{
4 We focus on upward occupational mismatch, which refers to the situation in which a worker's educational attainment (skill level) exceeds the educational qualification (skill level) required for the worker's job, leading to a condition of overeducation/overqualification (overskilling/skill surplus). The unprecedented rise in the supply of university and college graduates over the past few decades in several OECD countries and the more negative consequences compared to downward mismatch at both the individual and aggregate levels (for a review, see Hartog 2000; Rubb 2013; Brynin 2002; Tsang and Levin 1985; Cedefop 2010; Ortiz 2010; Quintini 2011 or Dolado et al. 2002) motivated our choice.
} 
between the different types of mismatch identified in Sect. 3. Our conclusions are presented in Sect. 5.

\section{Literature Review of the Approaches to Measuring Occupational Mismatch, Their Strengths and Limitations}

This section presents an extensive literature review of the different approaches used to conceptualise and measure occupational mismatch to provide a better understanding of current research on the topic and the empirical approach followed in Sect. 3.

For decades, the notion of occupational mismatch has been conceptualised and measured in different ways, generally by comparing a worker's competencies to the competencies required for his or her job (Desjardins and Rubenson 2011). However, owing to the difficulties involved in observing and measuring competencies, this phenomenon has largely been proxied by education mismatch (i.e., the match between a worker's attained education level and the education level required by the worker's job). The first contribution was provided by Freeman (1976), who introduced the notion of education mismatch, measured objectively by comparing a worker's level of attained education with that required by the worker's job. Later, in 1981, a paper by Duncan and Hoffman (1981) specifically addressed the problem of occupational mismatch and its effects on wages, and Oosterbeek (2000) subsequently presented a measure of education mismatch in the Mincer earning equation. Only recently has the phenomenon been addressed by considering the actual match between a worker's skill proficiency and the level of skills required by the worker's job, i.e., skill mismatch. As already highlighted in the Introduction, skills and education level are not synonymous. Education refers to an individual's qualifications at a given point in time, which are bound by differences across countries and cohorts for the same level attained. By contrast, skills are acquired and lost over an individual's entire lifespan, thereby providing a more concise and updated measure of competencies. Thus, while the methods discussed in this section to capture education and skill mismatch are considered closely related, it is important to bear in mind the distinction between these two constructs.

With this conceptual underpinning established, the second issue concerns the measurement itself. As mentioned above, overeducation (overskilling) ${ }^{5}$ occurs when the education level (skill level) of a worker is higher than that required by his or her job. Observing or measuring workers' education level is straightforward, whereas identifying workers' skill level is more difficult. The literature nevertheless has made extensive use of surveys such as the IALS, ALLS, and PIAAC to overcome this issue (although with all the caveats concerning whether the types of skills that these surveys measure are important in the labour market; see Sect. 2.2). However, measuring the education/skill level required by a job has always been more problematic (Verhaest and Omey 2006). Ideally, such a measurement would require (comparable) information about the demand side, which is often unavailable. Consequently, the literature has developed a number of different approaches, with the main distinction being between objective and subjective methods.

\footnotetext{
5 As stated in the Introduction, in this paper, occupational mismatch always refers mismatch in which individuals' education and/or skills are above those needed for their job (i.e., overeducation and overskilling). While undereducation and underskilling are also forms of occupational mismatch, their measurement is outside the scope of this paper.
} 
This section presents an overview of the measurements of both types of occupational mismatch used in the literature, highlighting the advantages and disadvantages of each.

\subsection{Education Mismatch}

As mentioned above, the first main distinction that can be made between different approaches to measuring education mismatch is between objective and subjective approaches (Groot and Maassen van den Brink 2000). Objective approaches rely on objective measures, such as the actual level of education attained (generally measured using either the ISCED classification or the number of years of education) and the level of education attained by peers working in the same occupation or the level of education considered appropriate for a job (Verhaest and Omey 2006). More specifically, two types of methods are used to take an objective approach to measuring education mismatch.

The first method is the normative/job analysis (JA) method, which measures the 'required' level of education for a certain job on the basis of an evaluation by professional job analysts. This method relies on an a priori equivalence between education and occupation, such as those provided in the US Dictionary of Occupational Titles (DOT). Based on this comparison, each worker is categorised as overeducated, undereducated, or matched (see for example Rumberger 1987; McGoldrick and Robst 1996). Note that, as with other measures proposed below, this method relies on the assumption that all jobs with the same title have the same educational requirement, which might not always be the case in reality. Conceptually, the JA method may be superior to the other method because making the call on which education level is required for a job is under the purview of trained job analysts. However, it is very costly to implement and is likely to become obsolete very quickly.

The second method is the statistical/realised matches (RM) method, which draws on the distribution of the workers' education levels within each occupation to infer the education level required for a job. With the mean (Verdugo and Verdugo 1989; Bauer 2002) or mode (Kiker et al. 1997; and Mendes de Oliveira et al. 2000) of the education level distribution for the worker's occupation group [normally defined based on the International Standard Classification of Occupations (ISCO)] used as a reference, mismatch situations are identified when the individual's education level deviates from the mean/mode by more than one standard deviation (sometimes two, to identify cases of severe mismatch). This method has the undisputed advantage of always being implementable because measures of mismatch based on it are computed directly from the data. Nevertheless, it presents a number of drawbacks. First, measures derived from this method tend to be rather sensitive to cohort effects. For instance, given the current trend of younger cohorts generally entering the labour market with higher qualifications than the existing work force, using the mode/mean education level for the entire work force within a given occupation, without a distinction regarding age, reflects the qualifications of people who were hired at different times. Hence, simply comparing this measure with an individual's level of education can lead to misleading conclusions about education mismatch. To solve this problem, several scholars have modified the RM method by considering cohorts rather than the population as a whole (Elias and Purcell 2004). Alternatively, Quinn and Rubb (2006) allow required education to vary with year of birth and survey year. Second, from a methodological perspective, the choice of, for example, one standard deviation as a threshold is completely arbitrary, and results tend to depend on the level of aggregation that is necessary to obtain a reliable distribution of education for occupations (identified using the 1- or 2-digit level of the ISCO). Similarly, the choice between using the mode and using the mean also relies on some degree of arbitrariness, although the former is usually preferred because using the 
mode as reference point has the advantage of being less sensitive to outliers and technological change. Finally, the RM approach allows only one education level to be appropriate for each occupation, which may not capture reality for particular occupations, especially if they are broadly defined.

Subjective approaches (Self-Declared/Self-Reported/Self-Assessment-SA) rely on information provided by workers and include two types of methods. First, direct selfassessment (DSA) directly asks workers' opinion regarding whether their job matches or is related to their level of education. Second, indirect self-assessment (ISA) asks workers about the education requirements of their current job. Key studies in the literature adopting the DSA approach include Groeneveld (1997), Chevalier (2003), and Verhaest and Omey (2006). Alternatively, for ISA, we find Duncan and Hoffman (1981), Hartog and Oosterbeek (1988), Sicherman (1991), Sloane et al. (1999), Battu et al. (2000), Allen and van der Velden (2001), Dorn and Sousa-Poza (2005), Green and Zhu (2010), Frei and Sousa-Poza (2012), and Baert et al. (2013), among others. The literature distinguishes between the education level required to get a job and the one required to do the job; moreover, some authors have used different expressions (e.g., 'appropriate' education level; Allen and van der Velden 2001) ${ }^{6}$ to identify these separate concepts. Distinctions based on further dimensions (e.g., formal vs. informal education; best preparation vs. preparation needed to perform) are also made (Leuven and Oosterbeek 2011).

Subjective reports by respondents are, of course, particularly vulnerable to measurement errors, and such errors can vary from respondent to respondent. For example, individuals may easily overstate the requirements of their job to inflate the status of their position. They might also be poorly informed about the performance of people with different levels of education/skills. Further, especially concerning education, workers' answers may simply reproduce current hiring standards, which may cause problems if education levels in the labour force increase over time and if employers increase their hiring standards even if the jobs themselves have not changed. However, subjective approaches have the advantage of providing measures that are easily observable, specific to the job of the respondent, and up to date. Subjective measures of the incidence of education mismatch are typically found to exceed those obtained via objective measures (Groot and van den Brink 2000). Nevertheless, the various approaches to estimating the incidence and returns to education mismatch tend to yield broadly consistent conclusions (McGuinness 2006).

A number of mixed methods have also been used in the literature, whereby both objective and subjective methods are combined, depending on data availability (Cedefop 2010; OECD 2013). For example, Chevalier (2003) and Chevalier and Lindley (2009) mix the JA method with the subjective approach (DSA/ISA) to obtain a more refined measure of overeducation. The authors use the JA method to determine whether an individual is overqualified, and they then use a subjective question capturing individuals' 'satisfaction regarding the match between education and job' to divide overqualified individuals between those who are apparently overqualified (normatively overqualified individuals who are nonetheless satisfied with their match) and those who are genuinely overqualified (normatively overqualified individuals who are also unsatisfied with their match).

A different approach related to wages is suggested by Nauze-Fichet and Tomasini (2002). A person is classified as overqualified if two-thirds of the individuals at the level of education immediately below the person are better paid. Indeed, all else being equal,

\footnotetext{
${ }^{6}$ According to the authors, 'appropriate level' might be preferable to the alternative of 'required level', as the latter expression may partly measure formal selection requirements, whereas the former is more likely to refer to actual job content.
} 
education should enhance individuals' work productivity and thus raise their expected wage rate. Thus, individuals who are paid significantly less than the wage corresponding to their level of education are considered to be overqualified.

\subsection{Skill Mismatch}

To address the limitations of using educational attainment or years of education to measure occupational mismatch, a new strand of studies uses individual' skills as a potentially superior proxy for competencies. Nevertheless, using workers' skill level to measure mismatch also raises some concerns.

First, a limited number of surveys include directly observed measures of skills. Among such studies, Krahn and Lowe (1998) rely on data from the Canadian component of the IALS, whereas Desjardins and Rubenson (2011) use the ALLS. The recent release of PIAAC, however, represents an additional relevant source in this field (OECD 2013). Second, whether the skills measured are indeed the skills relevant for identifying a situation of skill mismatch may be unclear. As a general issue, not all specific skills are feasible to assess via survey instruments; indeed, in most cases, only a few direct measures of skills are available. With respect to this matter, the PIAAC survey assesses skills in literacy, numeracy, and problem solving in technology-rich environments. These skills are 'key information-processing competencies' and are identified as being relevant to adults in many social contexts and work situations. Thus, although it is unclear whether the skills captured in the surveys perfectly reflect the range of tasks that are important for labour market success and productivity, these skills can nevertheless be relied on for fully integrating and participating in the labour market, education and training, and social and civic life (OECD 2013).

The methods that have been adopted to measure skill mismatch can generally be distinguished according to the same types of approaches presented for education mismatch. As for measures of education mismatch, measures of skill mismatch can be derived based on a self-declared assessment (DSA or ISA) of skill use. Key studies in the literature adopting this approach include Halaby (1994), Allen and van der Velden (2001) Mavromaras et al. (2007b), Green and McIntosh (2007), and Vieira and Cabral (2005), among others. With this approach, for example, workers are asked to what extent they utilise their skills and knowledge in their work or to what extent they feel that they need to receive further training to adequately perform their job.

Two broad categories can be identified when applying the realised match $(R M)$ method to measure skill mismatch. The first category includes techniques resembling the standard RM approach, in which the distribution of skill levels is calculated for each occupation and in which workers who deviate from the mean or mode by more than a certain value (generally one or two standard deviations) are classified as over- or underskilled. Alternatively, skill match and mismatch can be determined on the basis of reported engagement in certain skill-related tasks at work on one hand (with engagement intended to represent the job requirement) and direct measures of the skills possessed by workers on the other (see Krahn and Lowe 1998; Desjardins and Rubenson 2011, whose approach is adapted from the methodology devised by the former). Depending on the level of workplace engagement in tasks related to a certain skill, workers are classified in two groups: low to medium-low engagement (identifying low-skill jobs) and medium-high to high engagement (identifying high-skill jobs). The cutoff between high- and low-skill engagement can be based, for example, on whether the engagement scores are below or above the median level of workers (generally in the same 2-digit ISCO occupational group) or on whether 
workers engage in tasks that are related to the specific skill at least once per week on average. Similarly, individuals can be distinguished as low skill or high skill according to some direct measure of their skills. According to Desjardins and Rubenson (2011), overskilling (or surplus mismatch) occurs when an individual possesses medium to high skills but reports low to medium-low engagement for that skill.

An alternative measure has also been developed by Allen et al. (2013) based on PIAAC data. For each domain (numeracy and literacy), the authors standardise the relevant measure of skill level and skill use and then subtract each standardised measure of skill use from the corresponding standardised measure of skill level; all individuals with a value greater than 1.5 on this difference variable are defined as 'underutilised' (i.e., overskilled). A few concerns have been raised in the literature regarding the use of skill engagement as a proxy for skill requirements for a certain job. First, skill engagement is generally measured in terms of the incidence and frequency of activities involving specific skills. This procedure can misrepresent the relevance of certain skills and, consequently, their impact on job performance, as important factors such as criticality and complexity are not taken into account. In this respect, however, Desjardins and Rubenson (2011, p. 26) note that 'analysis of these [skills] measures show systematic variation across industry, occupation, and education categories as one would expect from reasonably valid measures of literacy and numeracy behaviours'. Second, the frequency of skill use is a different concept than the required skill level. Pellizzari and Fichen (2013) argue that skill use can hardly be considered a measure of job requirement because the level of effort in the deployment of skills (i.e., skills use) on the job is actually an endogenous choice of the worker. As an additional issue, they note that

proficiency and use are very different theoretical concepts and they can hardly be represented along the same metrics. In fact, they are derived from structurally different pieces of information: indicators of skill use normally exploit survey questions about the frequency (and/or the importance) with which specific tasks are carried out in a certain job, whereas skills proficiency is usually measured through cognitive tests.

While acknowledging that the measure that they construct is, strictly speaking, a measure of skill use relative to one's own skill level, rather than a measure of skill mismatch, Allen et al. (2013) maintain that an analysis based on this approach can nevertheless provide relevant results. According to the authors,

there is in fact strong empirical evidence that skill use is quite strongly related to required skill level. Additionally, skill use-and skill mismatches derived by using skill use in combination with skill level—show clear and plausible relationships with labour market outcomes. Finally, [...] efficiency considerations dictate that the greatest productivity is achieved when the people with the highest level of a given skill in the population are the ones who are using that skill the most often, and that the least skilled are those that use that skill the least often (Allen et al. 2013, p. 4).

Moreover, the authors claim that when their measure is defined as one of skill use relative to skill level, the scales on which the two components are measured no longer need to 'mesh up perfectly, because a higher or a lower score simply means that skill use is higher or lower than one would normally expect for a worker with that level of skills'. Further, because they consider fairly extreme mismatches (1.5 standard deviations above or below the 'expected' skill use for a given skill level), they maintain that they 'can be fairly 
confident that workers who are identified as mismatched indeed have a level of skill use that is unusually high or low for workers with a comparable skill level'.

A more recent measure of skill mismatch is the one proposed by the OECD in 2013 by Pellizzari and Fichen (2013). In developing this measure of skill mismatch, the authors note how most of the other approaches aiming to infer job requirements on the basis of information drawn from realised matches (to solve the problem of the constant lack of information about the demand side) adopt a very practical empirical approach to the issue. They therefore aim to devise a methodology that is derived from theory, clearly delineating the assumptions made. The measure of skill mismatch that they create, which can be considered to belong to the category of mixed methods, combines the overskilling/skill deficit self-assessment of individuals and individuals' proficiency score in each domain (i.e., literacy, numeracy, and problem solving in technology-rich environments). Thus, workers are classified as well matched in a domain if their proficiency score in that domain is between the minimum and maximum score $^{7}$ observed among workers in the same occupation and country who report being neither over- nor underskilled. By contrast, workers are overskilled (underskilled) in a domain if their score is higher (lower) than the maximum (minimum) score of self-reported well-matched workers. According to OECD (2013),

The OECD measure of skills mismatch is an improvement over existing indicators as it is more robust to reporting bias, such as over-confidence, and it does not impose the strong assumptions needed when directly comparing skills proficiency and skills use. However, this approach does not measure all forms of skills mismatch; rather, it focuses on mismatch in the proficiency domains assessed by the Survey of Adult Skills, leaving out mismatch related to job-specific skills or that involving more generic skills (OECD 2013, p. 172).

Finally, some methods of evaluating occupational mismatch that include both education- and skill-based measures have been developed in the literature. For instance, Green and Zhu (2010) build on Chevalier's (2003) work and distinguish between types of overeducation, according to whether the overeducation is associated with a perceived underutilisation of skill (or not). Cases of overqualification are further distinguished between situations of formal overqualification, which occur when individuals are mismatched in terms of education level but matched in terms of skills, and situations of actual overqualification, which occur when the individual both has an education level that exceeds the required level and uses little or even very little of his or her skills in his or her current job.

\subsection{State of the Art of the Empirical Evidence on Skill and Educational Mismatch}

Similarly to this paper, a few scholars have attempted to understand the relationship between skills and educational mismatch using a common survey able to provide information on both phenomena. Among these studies, Verhaest and Omey (2006) compare four different measures of overeducation based on Flemish data collected for only 23-yearolds, finding substantial differences across the examined measures and in their effects on several labour market outcomes. Other papers have attempted to contrast overeducation

\footnotetext{
7 To limit the potential impact of outliers on these measurements (and to allow for the heterogeneity of jobs within occupations that, despite the theoretical assumption of all jobs being identical within occupations, does exist in practice), the 5th and 95 th percentiles instead of the actual minimums and maximums are used.
} 
with overskilling, but they have generally relied on graduate surveys and subjective measures and have focused on only a few countries. For instance, Allen and van der Velden (2001) use Dutch data on graduates to compute subjective measures of education and skill mismatch and conclude that the former is neither a necessary nor a sufficient condition for the latter. In addition, Allen and de Weert (2007) use data on graduates from 5 European countries to analyse the relationship between (subjective) education mismatch and skill mismatch and conclude that the two phenomena are indeed related but are far from interchangeable. For UK graduates, Green and McIntosh (2007) find a moderate correlation between (objectively measured) overeducation and (subjectively measured) overskilling (0.2). Mavromaras et al. (2007a, b) further show that $50 \%$ of overeducated Australians consider themselves to be matched in terms of skills. In general, these papers show that different measurement methods provide different results and that a positive, but weak, correlation exists between education mismatch and skill mismatch.

This review of the different measures used in the literature suggests that a continuous effort is required to better understand the concept of occupational mismatch. We devote the remainder of the paper to contribute to the literature further empirical evidence on the measurement of this concept.

\section{The Survey of Adult Skills (PIAAC)}

The Survey of Adult Skills is an international survey conducted as part of the Programme for the International Assessment of Adult Competencies (PIAAC). The survey measures key cognitive and workplace skills that are needed for individuals to participate in society and for economies to prosper. Using household interviews, the survey directly assesses the skills of approximately 150,000 working-age adults (16-65 years old) surveyed in 24 countries. The survey is the outcome of collaboration between the participating countries, the OECD secretariat, the European Commission, and an international consortium led by the Educational Testing Service (ETS) (OECD 2013).

The skills tested in PIAAC are literacy, numeracy, and problem solving in technologyrich environments. ${ }^{8}$ Several items in each of the three domains are answered by each respondent, and his or her performance is summarised in proficiency levels measured on a scale from 0 to 500 points, which is then divided into skills levels (from below 1 to 5 for literacy and numeracy; from below 1 to 3 for problem solving). Contextual questionnaires collect a broad range of information, including information not only on educational attainment but also on family background, linguistic background, working status, occupation and skill use at work and in other contexts, such as the home and the community.

In this paper, we focus on literacy and numeracy skills. ${ }^{9}$ The analysis is performed on the 17 European Union member states that participated in the survey include Austria,

\footnotetext{
${ }^{8}$ In PIAAC, literacy is defined as 'understanding, evaluating, using and engaging with written texts to participate in society, to achieve one's goals, and to develop one's knowledge and potential'. Numeracy is defined as 'the ability to access, use, interpret and communicate mathematical information and ideas, in order to engage in and manage the mathematical demands of a range of situations in adult life'. Finally, problem solving is defined as 'using digital technology, communication tools and networks to acquire and evaluate information, communicate with others and perform practical tasks'.

9 We disregard problem solving because the test for problem solving is administered only to people who report having some computer experience, which is not a representative sample of the population. Furthermore, there is no measure of skill use in the problem-solving domain, which prevents us from computing some of the indicators that are used in the literature.
} 
Belgium, Cyprus, the Czech Republic, Denmark, Estonia, Finland, France, Germany, Ireland, Italy, the Netherlands, Poland, the Slovak Republic, Spain, Sweden, and the United Kingdom.

The PIAAC sample was used to compute the different measures of mismatch consists of employed individuals only, excluding self-employed. ${ }^{10}$ Further, following Allen et al. (2013), we decided to drop individuals who, despite being formally in employment (objective status), are self-reportedly pupils/students or apprentices/interns (subjective status). As the authors explain, the exclusion of students is motivated by the fact that

student jobs are often low-skilled temporary jobs taken for the sole purpose of helping the individual or his/her family pay for the expense of obtaining an education. Apprenticeships and internships are excluded because they are not purely work, but a combination of education and work (ibidem, p. 6).

We use subjective status to identify students, rather than the objective status for individuals who are currently in formal education because we do not want to exclude from the sample individuals who are enrolled in some type of (possibly part-time) education but who nevertheless perform paid work as their main activity.

The final sample size is approximately 55,000 individuals. Table 1 provides an overview of the characteristics of the sample, showing the working sample by country and the proportions of individuals by sex, age group, education level, ${ }^{11}$ and occupation type. ${ }^{12}$

\subsection{Description of the Education and Skill Mismatch Indicators Used and Results}

Beginning with the literature review of the different approaches to measuring occupational mismatch described in the previous section, we use PIAAC data to construct a number of mismatch indicators based on data availability. In total, 20 different overeducation and overskilling indicators ${ }^{13}$ are computed, all of which are dummy variables that equal 1 if an individual in our sample is overeducated or overskilled, according to the corresponding measure, and 0 otherwise. Table 2 contains the procedure followed to replicate each indicator, with the reference to the authors who first implemented it, when appropriate. We compute 8 variables for education mismatch, including six objective and 2 subjective measures. The former use education level or years of education as the educational attainment variable, consider the aggregation of occupation definitions at the ISCO 1 or 2-digit levels, and perform the computation by age cohort or not. The subjective variables

\footnotetext{
${ }^{10}$ We exclude self-employed individuals because they present very peculiar and diversified features, especially in certain countries; therefore, this subpopulation is not comparable to the rest of the employed population. This approach is also followed by the OECD; see Pellizzari and Fichen (2013).

${ }^{11}$ We distinguish between three categories—low, medium and high—depending on ISCED 1997 level; the first includes individuals with lower secondary education or less; the second is composed of individuals with upper secondary (ISCED 3A-B, C long) or post-secondary, non-tertiary education (ISCED 4A-B-C); the third group is composed of individuals with tertiary education (ISCED 5A-B, 6).

${ }^{12}$ Occupation types are defined based on the ISCO category. Skilled occupations include, e.g., legislators, senior officials and managers; professionals; technicians and associate professionals (ISCO 1 digit categories 1, 2 and 3); semi-skilled white-collar occupations include, e.g., clerks; service workers and shop and market sales workers (ISCO 1 digit 4 and 5); semi-skilled blue-collar occupations include, e.g., skilled agricultural and fishery workers; craft and related trade workers; plant and machine operators and assemblers (ISCO 1 digit 6, 7 and 8); finally, unskilled (or elementary) occupations include, e.g., labourers (ISCO 1 digit 9).

13 The terms 'mismatch indicators' and 'mismatch measures' are used interchangeably in this paper.
} 


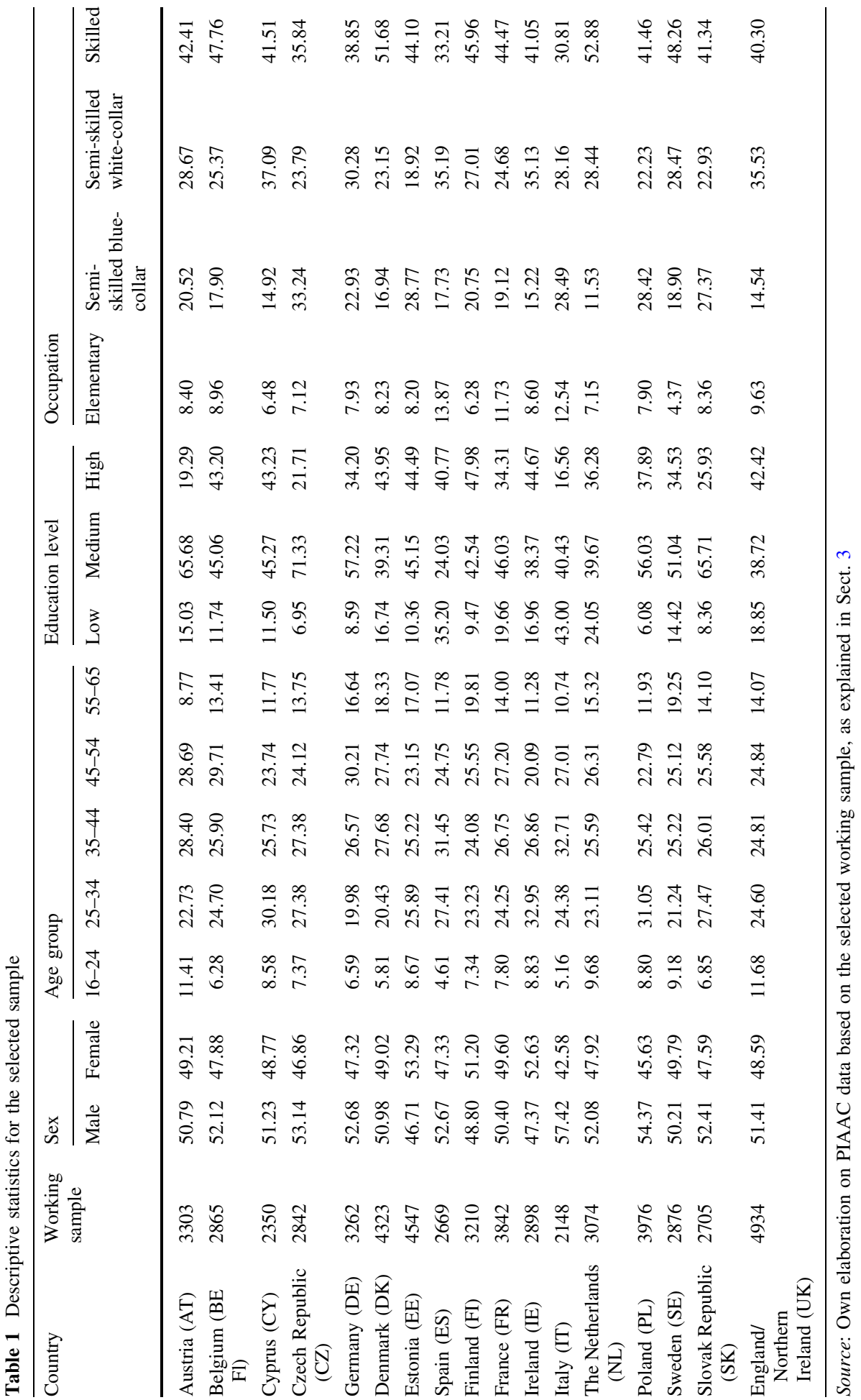




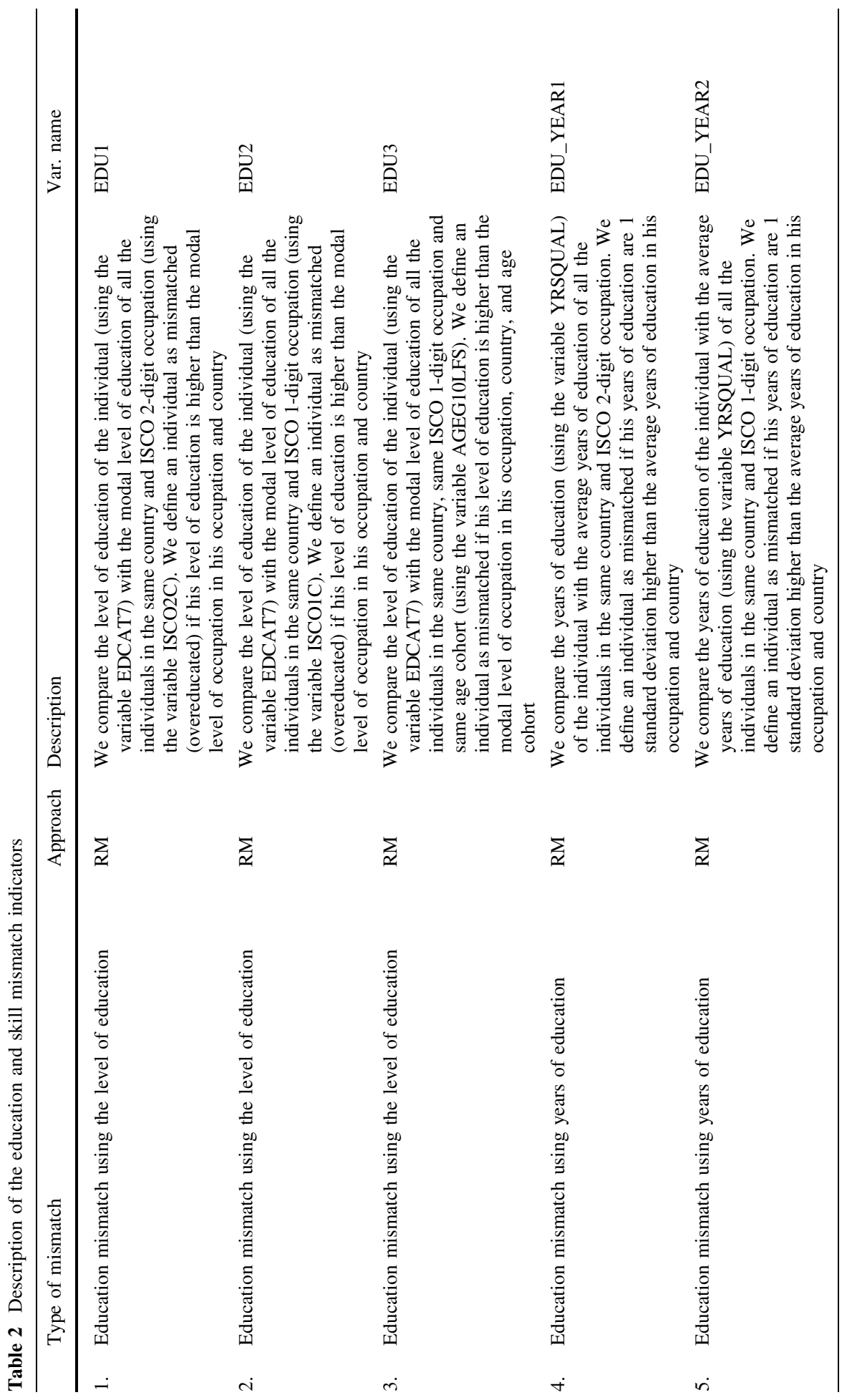




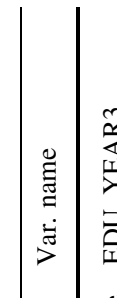

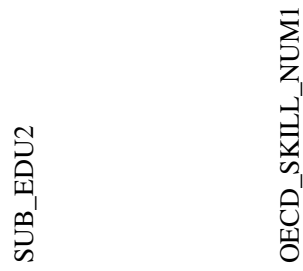

\section{空}

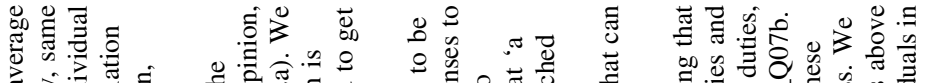

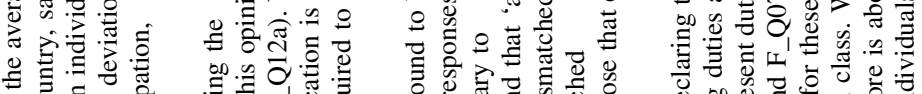

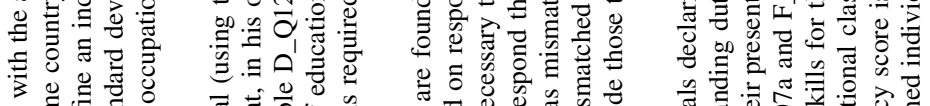

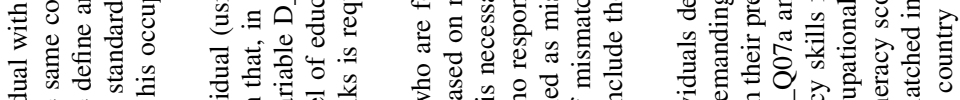

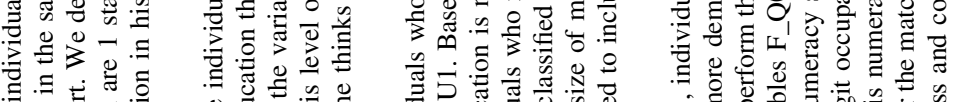

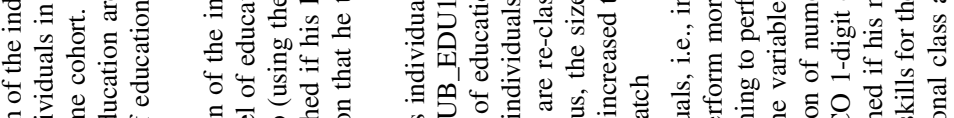

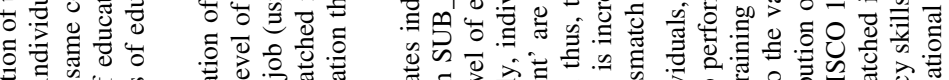

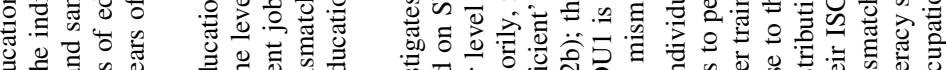

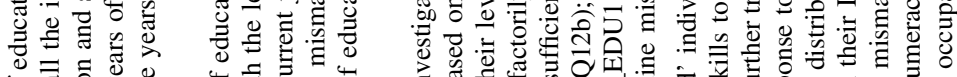

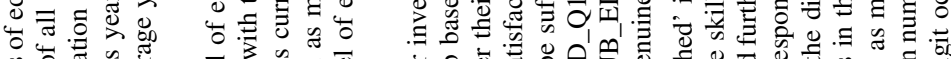

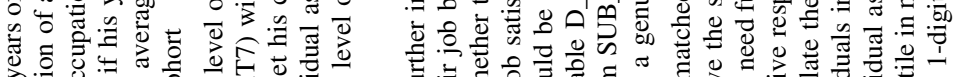

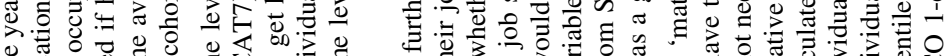

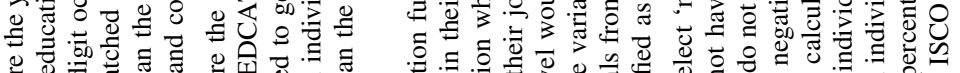

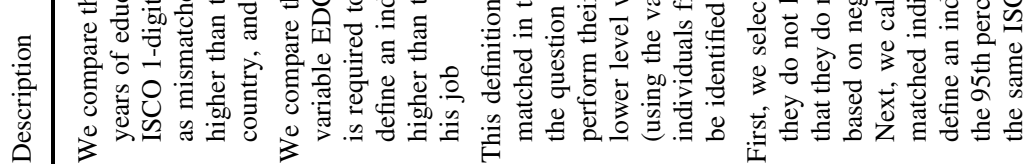

㭊

芯

$\stackrel{\vec{D}}{\ddot{x}}$

芯

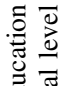

苋

ब。

要边

웛

我空

总

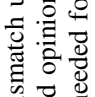

気

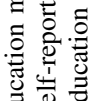

害吉

สี

히

氖立

艺

뉴웡

远范

彗

60 00

它

룰

㝵记

흥ㅎํ. 율

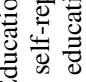

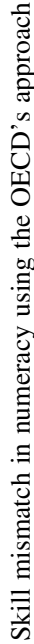

$\stackrel{\circ}{\circ}$

$\infty$

$a$ 


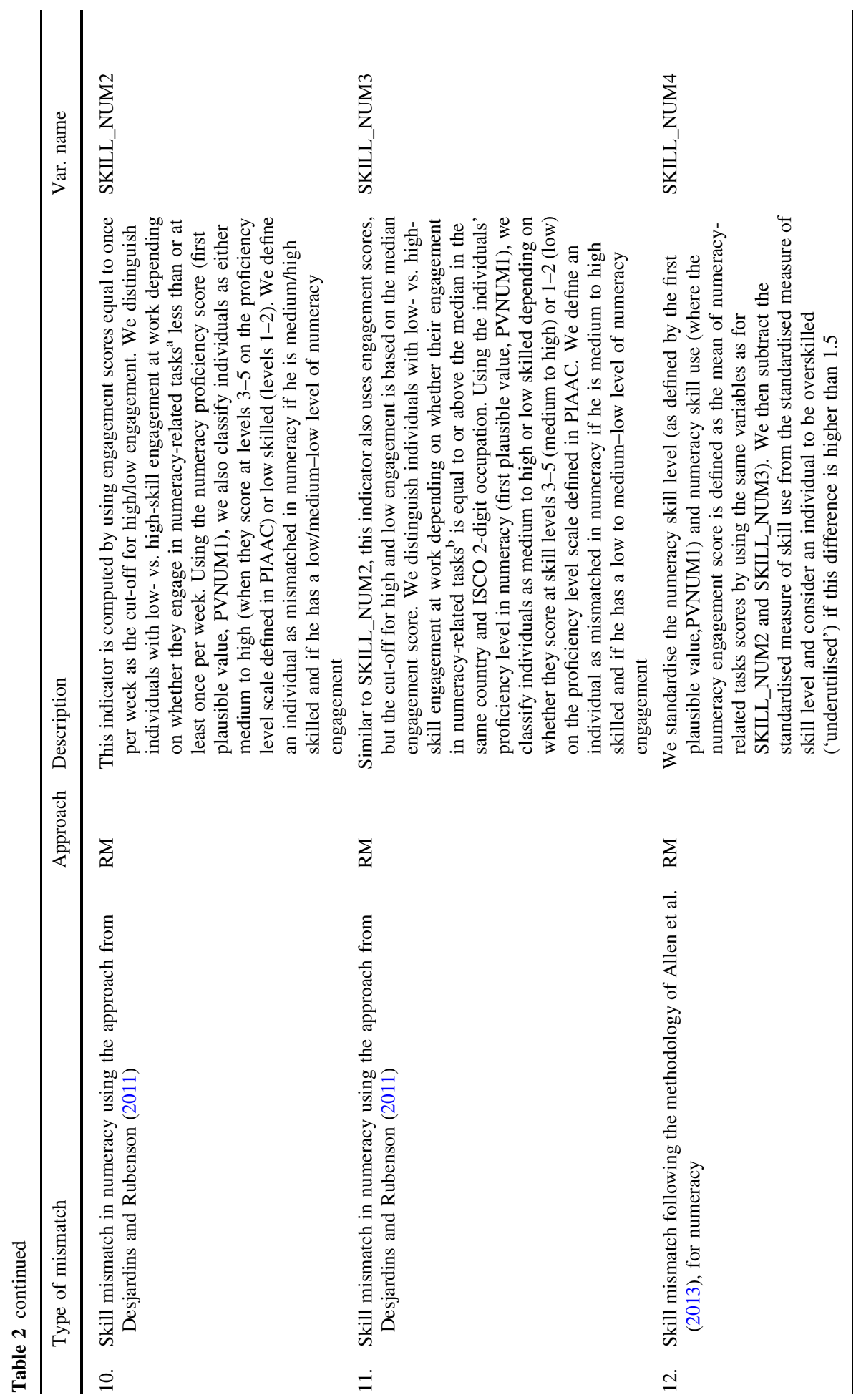




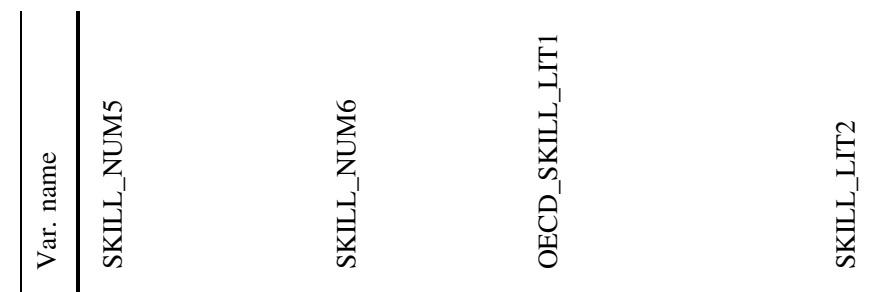

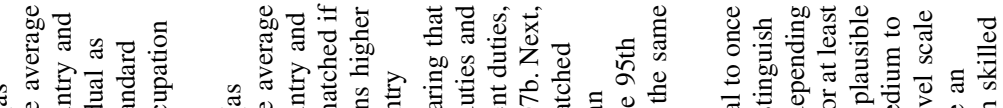

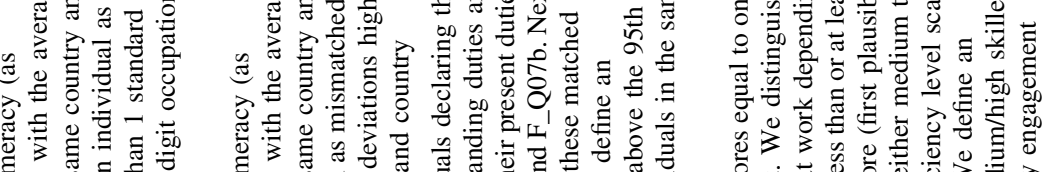

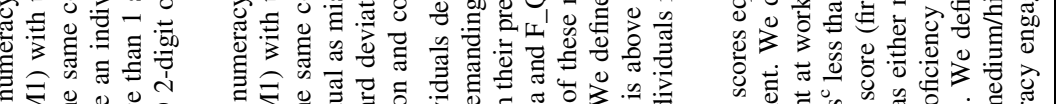

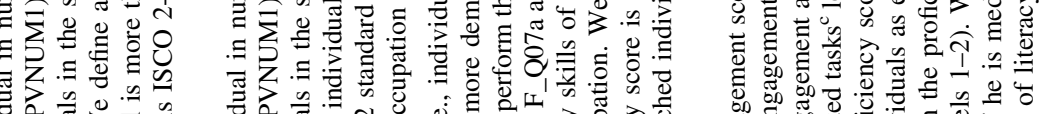

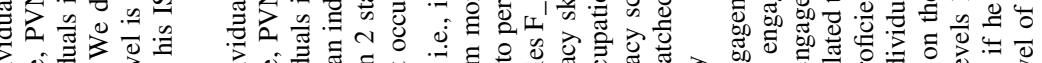

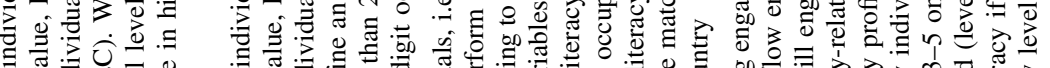

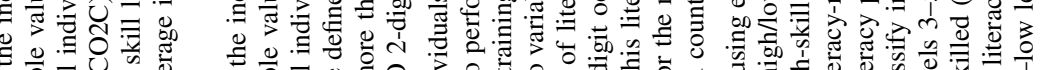

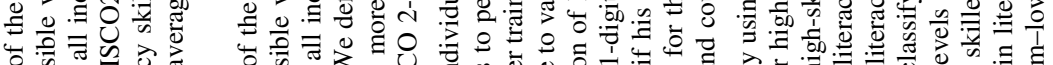

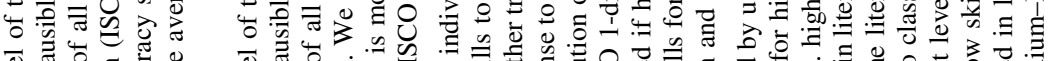

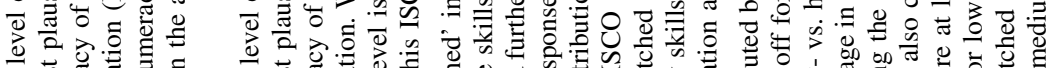

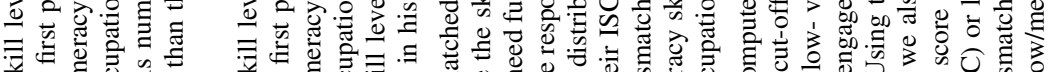

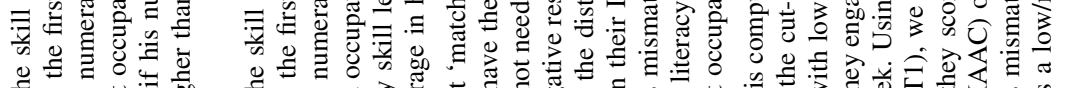

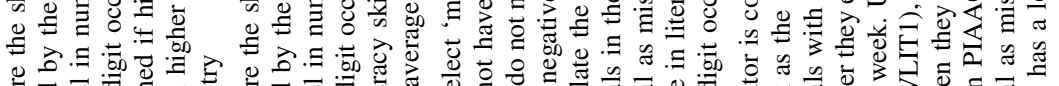

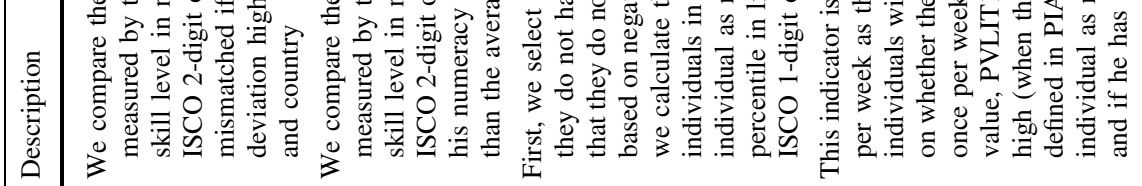

$\stackrel{\overrightarrow{0}}{\dot{x}}$

$\sum_{\propto}$

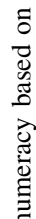

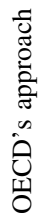

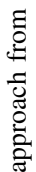

氖

$\Xi$

$\stackrel{0}{\leftrightarrows}$

귱

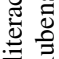

$\Xi \frac{9}{2}$

들

象

言

$\dot{I}$

in

$\stackrel{0}{0}$ 


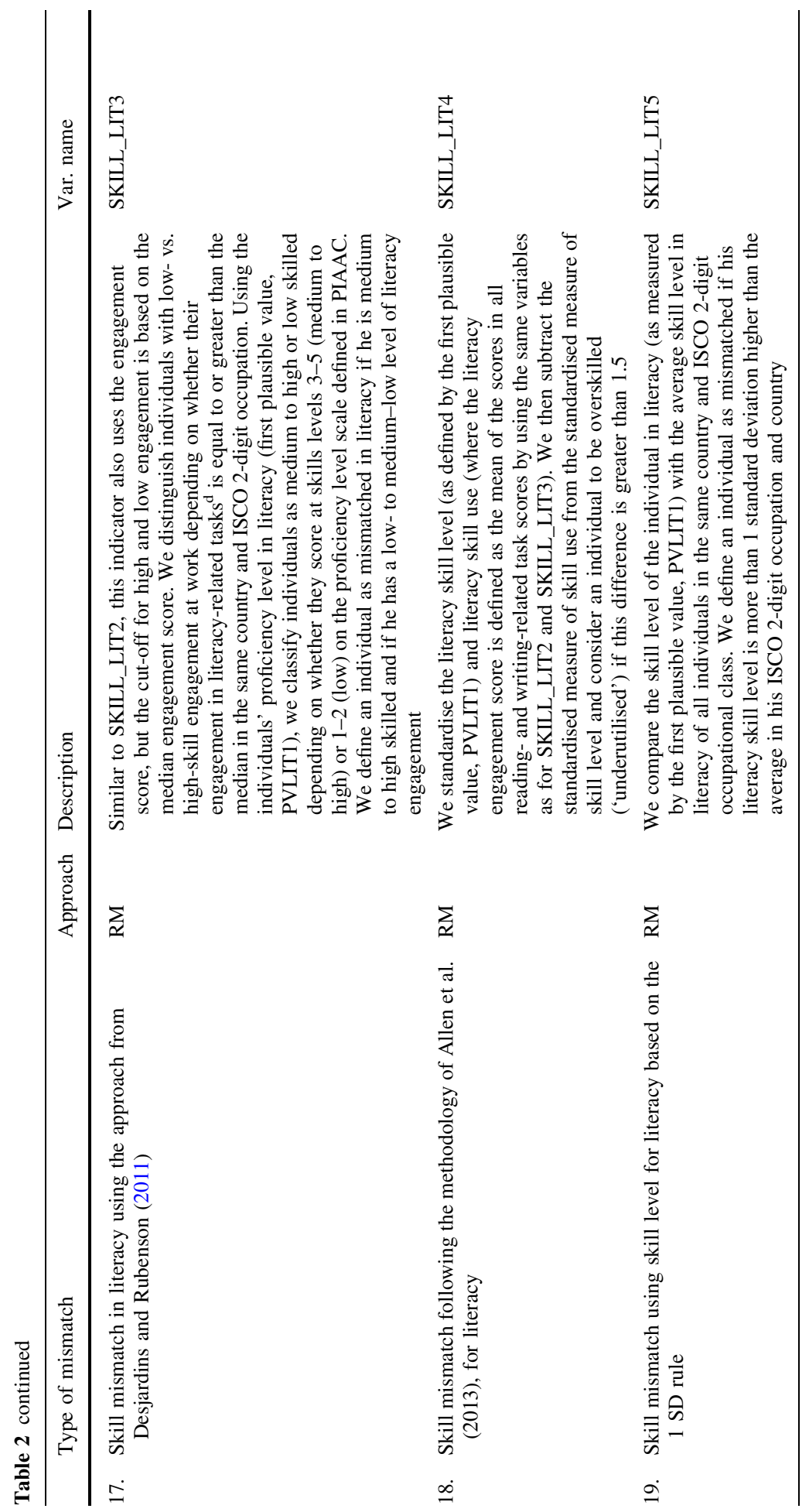




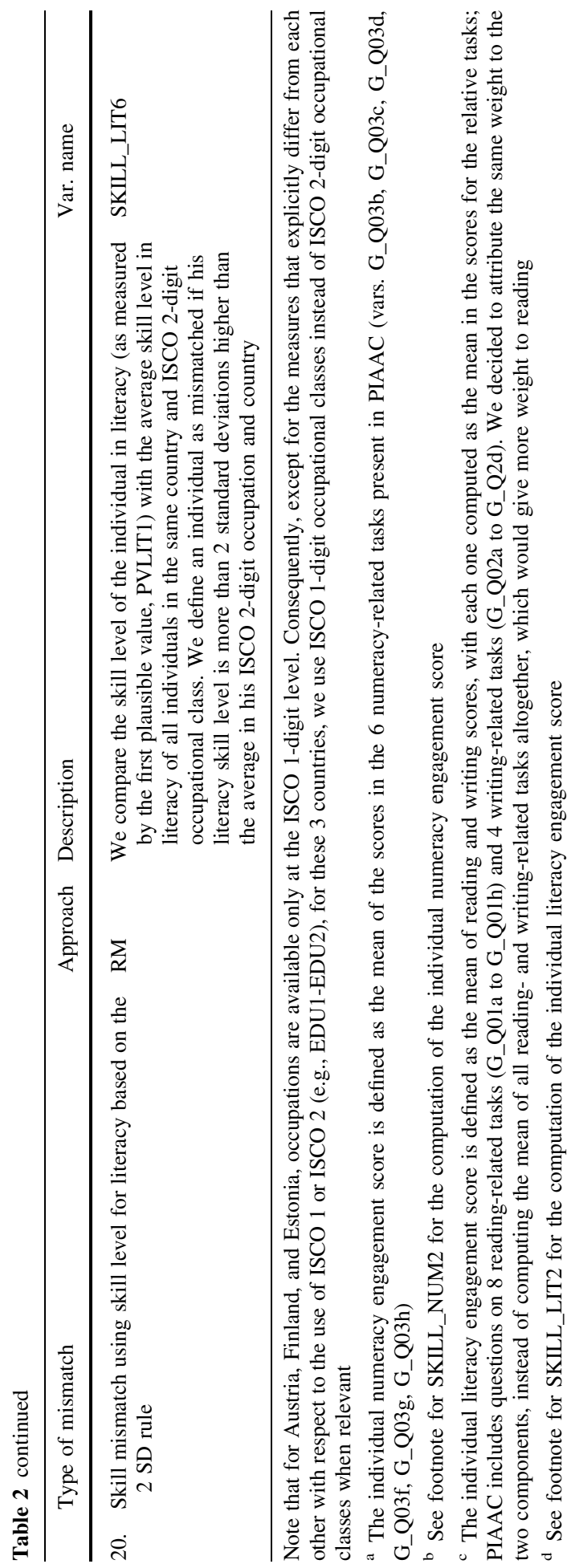


derive the required level of education by the self-reported level of education required to get a certain job or to perform the job satisfactorily. Concerning skill mismatch, we use six different ways of measuring overskill that, when applied to numeracy and literacy produce 12 indicators. One of these measures replicates the indicator used by the OECD in the PIAAC Skills Outlook 2013. Another two measures compare individuals' skills proficiency with the extent to which their skills are used at work (engagement score); the two measures differ in the cut-off for high/low engagement. Another measure uses the approach followed by Allen et al. (2013). Finally, two measures compare the skills proficiency of each individual with that of individuals working in the same occupation; the two measures differ in how far the former should be from the latter to be considered mismatched. Table 2 describes exactly how we build these indicators and the names given to them throughout the paper.

The lack of questions in the survey concerning the direct self-assessment of education mismatch prevented us from constructing DSA subjective measures of education mismatch. Measures within the JA approach for education mismatch are not reproduced because the existing literature is based mostly on the US DOT, which cannot be directly applied to a study on European countries. Finally, we decided not to reproduce mixed approaches between education and skill mismatch (e.g., Green and Zhu 2010) because the aim of the paper is to investigate the combination of information regarding education and skill mismatch; thus, a specific indicator involving a mixed approach was deemed unnecessary.

Table 3 reports the proportion of individuals who are mismatched (overeducated or overskilled) according to the different mismatch indicators. ${ }^{14}$ To compute point estimates, we used sampling weights.

The different measures reveal very different pictures of occupational mismatch, both within and across countries. On the one hand, some measures show pronounced variability between countries. For instance, EDU2 ranges from 10 to $39 \%$, SKILL_LIT2 ranges between 33 and $68 \%$, and SKILL_NUM2 ranges between 30 and $56 \%$. One the other hand, some measures show levels of mismatch consistent across all countries. For instance, the highest shares of mismatch are found for the indicators SKILL_LIT2 and SKILL_NUM2 for skill mismatch (i.e., the two measures based on Desjardins and Rubenson 2011, which use engagement scores equal to once per week as a cutoff for high/low engagement) and for the indicator SUB_EDU2 for education mismatch (i.e., mismatch using education level and self-reported opinions regarding the actual level of education needed to obtain and to satisfactorily perform the current job). The lowest incidence of mismatch is captured by the measures SKILL_LIT6 and SKILL_NUM6 (which, by definition, provide shares of approximately $2 \%$ because they consider individuals whose skill level is more than 2 standard deviations above the average in the respective ISCO 2-digit occupational classes and country). Similarly, EDU_YEAR1, EDU_YEAR2, EDU_YEAR3, SKILL_LIT5, and SKILL_NUM5, which are all based on the 1-standard-deviation rule, provide shares that are approximately $15 \%$. Low levels of mismatch are also registered in most of the countries when the measures SKILL_LIT4 and SKILL_NUM4 (i.e., the two measures

\footnotetext{
14 Note that, to guarantee sufficient variability to compute the indicators, the identification of matched and mismatched individuals was performed for each measure only when the number of sample observations on which the indicator was based was at least 20. This rule of thumb is particularly relevant when mismatched individuals are identified based on the comparison of skill levels in very narrow sub-groups, e.g., individuals working in the same country and ISCO 2 occupation level. This minimum threshold is a standard procedure in European surveys, such as EUSILC and LFS. Please note that the adoption of this rule implied that computing the measure of mismatch for all individuals was not possible for some indicators.
} 


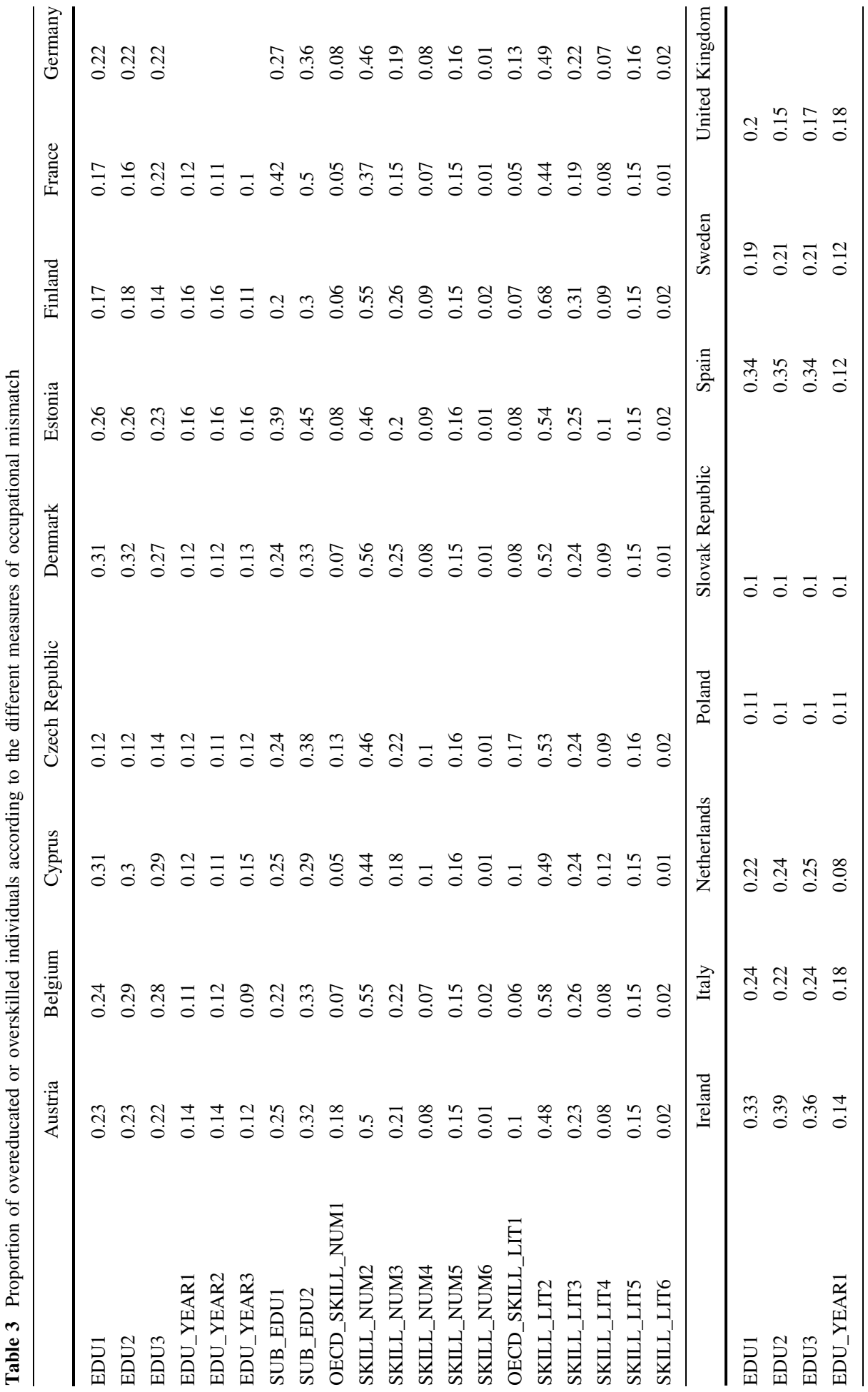




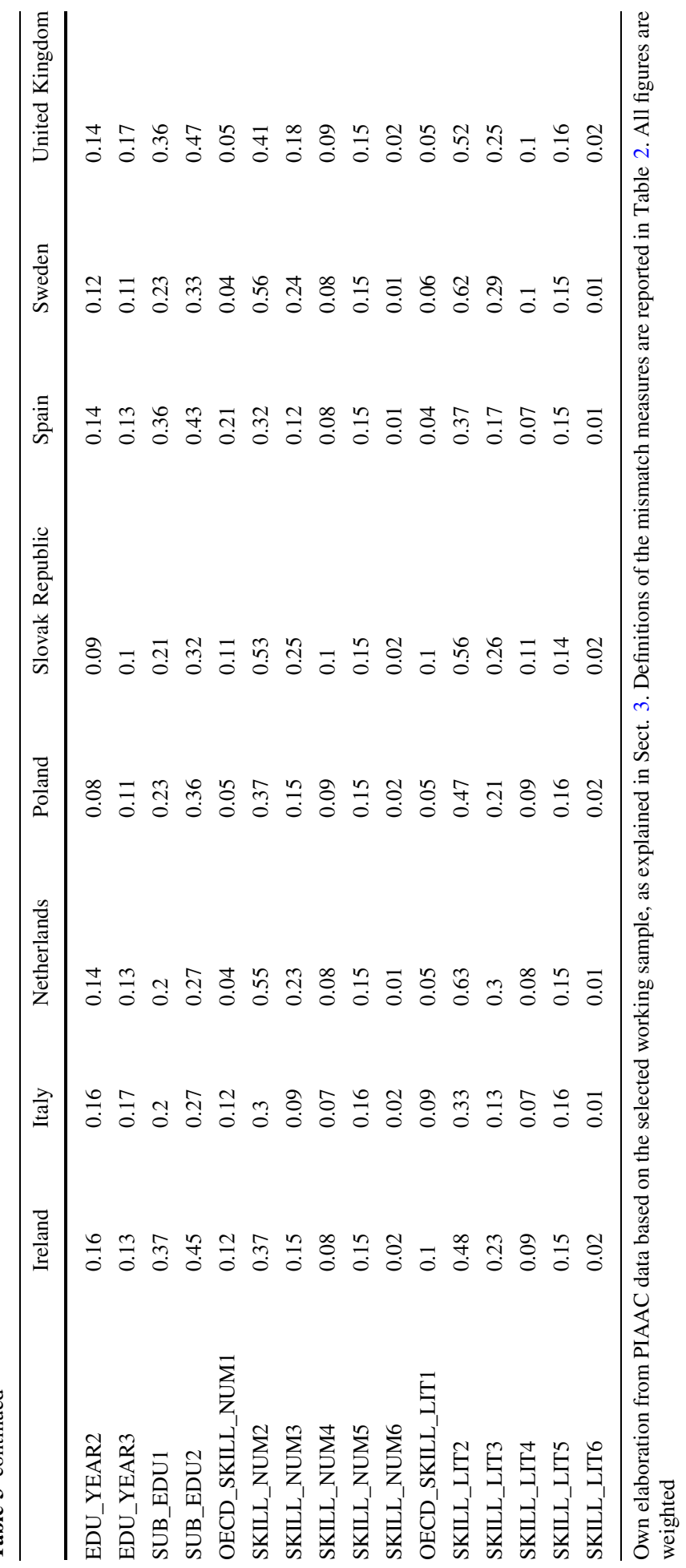


based on Allen et al. 2013, which compare standardised values of skill level and skill use) and the measures OECD_SKILL_LIT1 and OECD_SKILL_NUM1 (i.e., skill mismatch using the OECD approach) are used.

Given the patterns described above, within-country variability is generally very relevant, particularly in a few countries, e.g., Finland, the Netherlands, and Sweden, where the share of mismatched individuals is as high as above $60 \%$ in some cases.

This cross-country and within-country variability in occupational mismatch may be partly due to measurement error, but it certainly also results from the conceptualisation and operationalisation of occupational mismatch. Given the substantial differences, it is very difficult to draw a conclusion about which indicator should be used to identify occupational mismatch, and such a choice must be made carefully because the choice of indicator can lead to a very different picture of occupational mismatch both between and within countries and very different policy implications. Furthermore, from this analysis, it is unclear whether the indicators measure the same or different latent phenomena. We can see that the measures of education mismatch present less variability within country than the measures of skill mismatch. However, even in education mismatch, some discrepancy exists between the objective and subjective measures: in some countries, the former are larger than the latter, whereas in other countries, the opposite occurs. Regarding the skill mismatch measures, we see that the higher incidence of mismatch is concentrated in the measures that compare engagement scores and proficiency levels, whereas the measures that use the distribution of skills across the population present a clearly lower incidence of mismatch. The extent to which the differences observed across the different indicators imply that there are different phenomena of occupational mismatch being captured remains unclear. Thus, this issue requires further elucidation to better inform policy making regarding this labour market inefficiency. We contribute to this elucidation by conducting a Principal Component Analysis (PCA). The sole objective of following this approach is to understand whether more than one latent component is being captured. If only one component is identified, then we can conclude that regardless of the way that occupational mismatch is conceptualised and measured, all indicators capture the same phenomenon. If, on the other hand, there is more than one latent component, the conceptualisation and measurement of occupational mismatch is essential.

\subsection{Principal Component Analysis}

PIAAC data provide the unique chance to compute a reasonable number of measures of education and skill mismatch from the same data source. However, some of the reported indicators likely capture types of mismatch that are relatively similar to each other; thus, we implement a PCA aimed at developing better insight into the number of common latent dimensions that the mismatch measures may share. Ultimately, the objective of this analysis is not to use the predicted construct from the latent dimensions identified but to be able to compare across the different countries the potential multidimensional nature of occupational mismatch revealed by the PCA analysis.

As discussed in the previous section, our a priori expectation was to find two different components for education mismatch that distinguish between objective and subjective measures. Concerning skill mismatch, we expected that the OECD measure, representing a type of mixed indicator that takes into account both self-assessments and individual skills, could represent a separate component and that the rest of the measures may be distinguished depending on whether they rely on the distribution of skills in the population or the comparison between skills possessed and skills used at work. The procedure that we 
implement, however, groups the measures of mismatch into only 3 main components ${ }^{15}$ (see Appendix 1 for technical details):

1. The first component is defined mainly by measures of education mismatch based on both objective and subjective approaches, e.g., indicators EDU1, EDU_YEAR1, EDU_YEAR3, and SUB_EDU2.

2. The second component is defined mainly by measures of skill mismatch that are based on the distribution of skills in the population, e.g., indicators OECD_SKILL_NUM1, SKILL_NUM5, OECD_SKILL_LIT1, and SKILL_LIT5.

3. The last component is defined mainly by measures of skill mismatch that are based on the comparison between skills used at work and skills possessed, e.g., indicators SKILL_NUM3 and, SKILL_LIT3.

We also run the PCA by country and by age group, ${ }^{16}$ the results of which are mostly consistent with the results for the pooled sample: in the majority of countries, we find three components, one related to education, one related to skills based on the distribution of skills, and one related to skills based on engagement. ${ }^{17}$ The analysis by age group is conducted by dividing the pooled sample into 5 age categories: below 25, 25-34, 35-44, 45-54, and 55 and above. Again, the results by age are consistent with the results for the pooled sample. Thus, the PCA exercise has proven to be a useful tool to confirm the multidimensionality of the occupational mismatch concept. We now move away from the PCA approach to accomplish the second objective of our paper: investigating the extent to which the different dimensions of occupational mismatch vary and eventually overlap at the country level in Europe.

\section{The Multidimensional Nature of Occupational Mismatch: The Incidence of Different Types of Mismatch and Their Overlap Across Countries}

The analysis conducted thus far indicates that depending on the measure of occupational mismatch used, we may end up with different results and may measure different phenomena. Interestingly, the three dimensions identified by PCA highlight a difference related to the conceptualisation of occupational mismatch (education mismatch versus skill mismatch), as well as differences regarding the approach to measuring skill mismatch. This finding strengthens the idea that conceptualisation and measurement are important when investigating the occupational mismatch phenomenon, its determinants and implications. These issues should be carefully discussed. From this analysis, we can conclude that

\footnotetext{
15 The factor loadings are reported in Table 8. Note that the component that accounts for the largest part of the overall variability is actually the second component that we present here; for the sake of clarity, however, we present the education-related component first.

16 These results are available from the authors upon request.

17 In Germany, the variable 'years of education' is missing; thus, EDU_YEAR1 and EDU_YEAR3 are not used in the analysis. We also exclude the two measures built by following the OECD's approach because of their high number of missing values. Further, Belgium, Denmark, France, Ireland and Spain provide different PCA results with either different number of components (ranging from 2 to 4 ) or different aggregation of variables. However, because we will not fully exploit the PCA analysis and we will not use the predicted values of the latent dimensions identified to study country differences, we choose to select original variables from the three dimensions identified to advance to the next part of the paper. The results are available from the authors upon request.
} 
education mismatch is not a perfect substitute for skill mismatch and vice versa. Given the general lack of data on skill levels, researchers will more likely be able to measure education mismatch only. In such a case, it should be clarified that the phenomenon of skill mismatch is not being captured, and the inability to capture it might be particularly important for countries with a high degree of skill mismatch. If the researcher is able to measure skill mismatch, education mismatch can most likely also be measured. The researcher can then argue in favour of one or the other type of mismatch.

The existence of three different components of occupational mismatch also leads to another interesting insight: analysing the indicators from the three components separately yields only a partial view of this phenomenon. Indeed, the indicators are computed independently, and they do not provide any insight into the intensity and overlap of the types of mismatch. For instance, two countries may have similar levels of education and skill mismatch, which may lead to an initial interpretation that the mismatch situations in the countries are similar. However, suppose that individuals who are skill mismatched are also education mismatched in one country but that the two types of mismatch do not overlap in the other country. The analysis and the policy implications should certainly be different in these two countries. To facilitate the understanding of occupational mismatch, we highlight the potential overlap (or the lack of overlap) between the different types of mismatch identified and provide information about the most problematic type of mismatch in each country. To do so, we proceed by selecting one original indicator as representative of each of the three components identified through the PCA exercise. ${ }^{18}$ The selection is based on factor loading weights, sample size issues (e.g., the proportion of missing values), and theoretical grounds. The following variables are chosen to represent the three components:

1. For the component related to education mismatch, we choose the indicator EDU1, which identifies situations of mismatch in which the individual's education level is higher than the mode of the education level in the same ISCO 2-digit occupational class.

2. For the component related to skill mismatch based on the distribution of skills in the population, we choose the indicator SKILL_NUM5, which captures a mismatch situation in which the individual's skill level in numeracy is one standard deviation above the average numeracy skill level in the same ISCO 2-digit occupational class.

3. For the component related to skill mismatch, based on the comparison between skills used at work and skills possessed, we choose the indicator SKILL_LIT3, which captures situations of mismatch when an individual has a medium to high level of literacy skills but a low engagement in literacy-related tasks at work (following Desjardins and Rubenson 2011), with the median engagement score in the worker's ISCO 2-digit occupational class used as the cutoff for high/low engagement.

Table 4 summarises the link between the variables and the components: the first two columns indicate the broad category of mismatch and the type of approach within each category (which is described also in Sect. 2). Columns four to six describe how the variable is built, i.e., the education/skill measure that is considered and the reference that is

\footnotetext{
18 Instead of continuing with the PCA approach and predicting the 3 components by using the factor loading weights, we select one original measure for each component. We use this approach because the interpretation can be tricky when the predicted factors are considered. In particular, the factors that will emerge will be continuous variables centred at 0 and mutually orthogonal and that capture a latent dimension of mismatch. Thus, the proper interpretation is not immediately apparent, and if they are incorrectly interpreted, they variables can lead to misleading conclusions.
} 


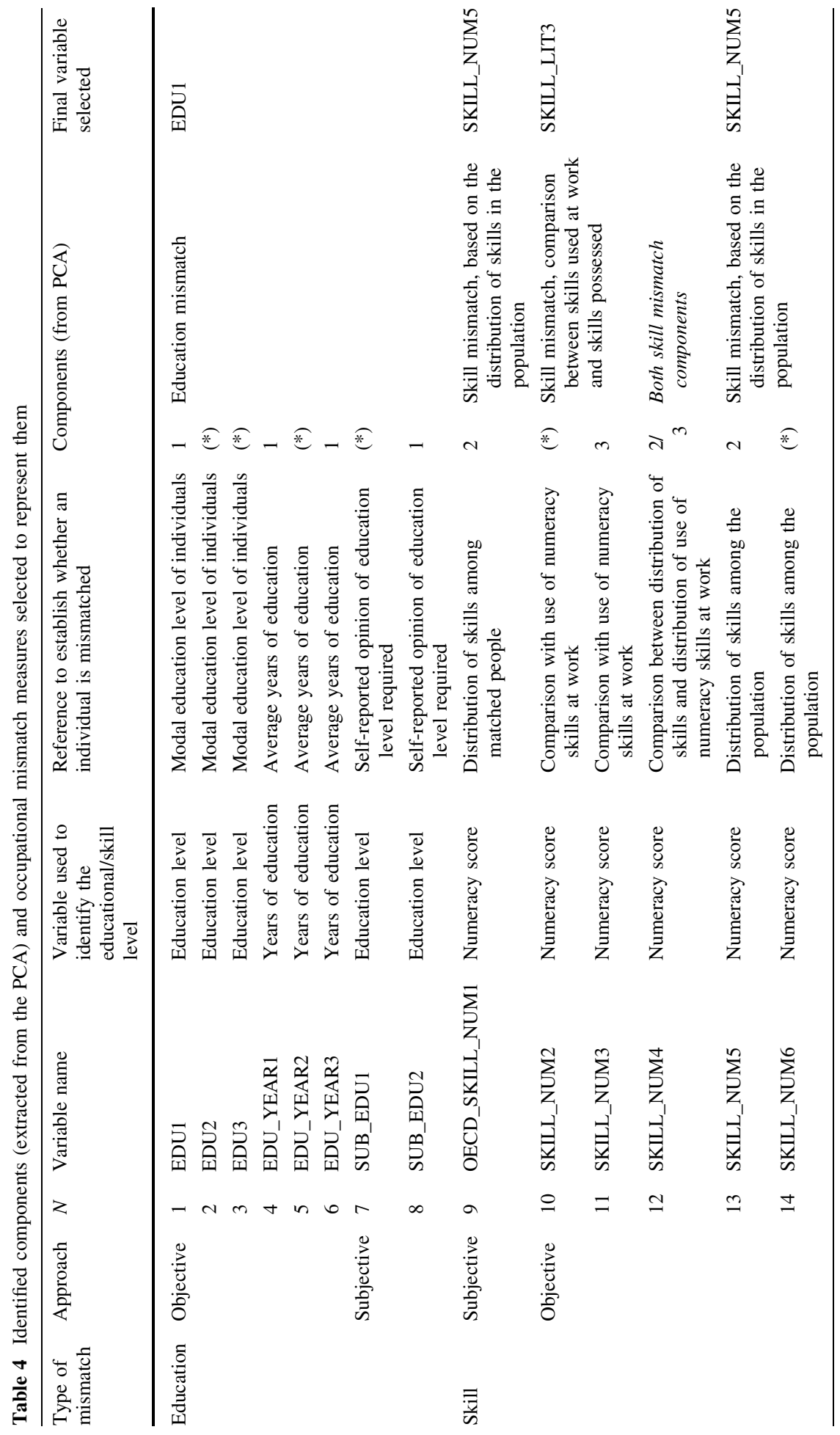




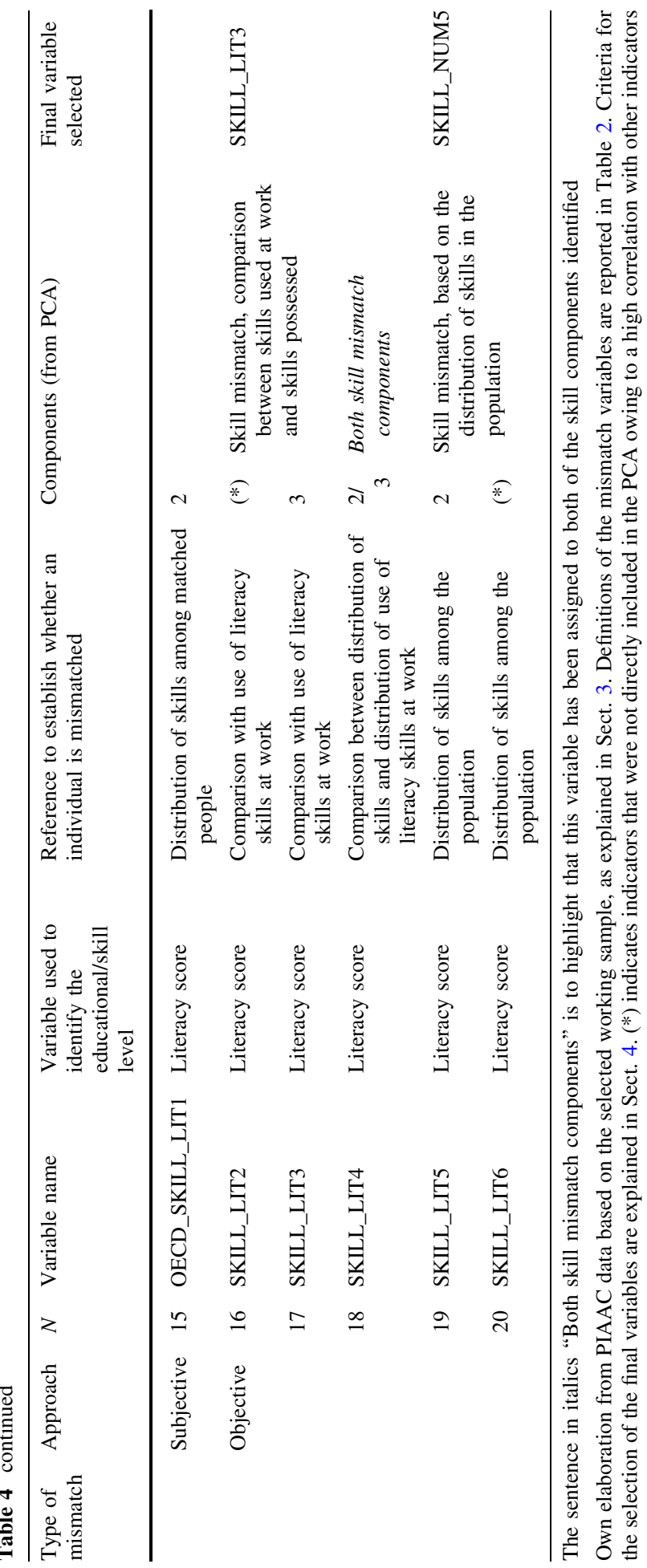


used to establish whether an individual is mismatched. The last two columns show how indicators are 'grouped' by the PCA in the three different components (based on how strongly they contribute to defining a component) and, within each component, which variable is finally selected as the representative of the component to which it belongs. ${ }^{19}$

We now turn to the analysis of the incidence of occupational mismatch at the individual level. Thus, we combine the mismatch information from the three representative indicators by allocating each individual in the sample to only one of the following four different categories:

(a) Matched: individuals who are not mismatched in any of the three indicators considered, i.e., not mismatched with regard to SKILL_LIT3, SKILL_NUM5, or EDU1;

(b) Severely/mixed mismatched: individuals who are mismatched with respect to both education and skill, i.e., mismatched on both EDU1 and either SKILL_LIT3 or SKILL_NUM5 (or both);

(c) Skill mismatched: individuals who are mismatched on dimensions associated with skills alone, i.e., mismatched on SKILL_NUM5 and/or SKILL_LIT3;

(d) Education mismatched: individuals who are only education mismatched, i.e., mismatched on EDU1 alone.

Once we have grouped the individuals in the four groups, we then observe the distribution of the categories in each country to determine the extent of the mismatch problem in each country, the percentage of mismatched individuals, and the predominant type of mismatch for each country. ${ }^{20}$

Table 5 reports the percentage of people in each category and per country, delivering interesting analyses. ${ }^{21}$ On average, $60 \%$ of the European population is occupationally matched, with values ranging from less than $50 \%$ for Cyprus, Denmark, Estonia, and Ireland to more than $60 \%$ for France and Poland. ${ }^{22}$ Moreover, the share of severely/mixed mismatched people is generally rather low $(8 \%)$ and stable across Europe, while the rest of the population share is split between individuals who are only skill mismatched or only education mismatched. This result supports the notion that skill mismatch and education mismatch provide a different picture of and different information regarding occupational

\footnotetext{
${ }^{19}$ As an additional robustness check, to verify whether the three measures of mismatch selected after the PCA are correlated (and whether they therefore provide the same information), we first rank the countries according to the level of mismatch identified by each of them and then estimate the Kendall correlation of these rankings. The results confirm that there is no significant correlation between the measures, indicating that they do indeed capture different aspects of mismatch.

${ }^{20}$ We replicate the analysis in this section using different indicators as representatives of their corresponding components. For component 1, we always use EDU1, because it clearly has a higher factor loading than SUB_EDU2. For component 2, we use SKILL_LIT5 instead of SKILL_NUM5, because it has a similar factor loading. For component 3, we use SKILL_NUM3 instead of SKILL_LIT3, because it also has a similar factor loading. The results presented in Table do not change significantly with this different set of representative indicators. These results are available from the authors upon request.

21 Given that the choice of indicators that are representative of the three dimensions is based, among other criteria, on the number of missing values, the analysis presented here is based on almost the entire working sample selected at the beginning of the study: of the 55,000 individuals, only roughly 1600 are not used because of missing observations in one of the three measures.

22 Results for Belgium, Denmark, Spain, France and Ireland should be interpreted with caution because the variables chosen may not fully represent the components identified in the remaining countries, as indicated in footnote 17; these results are nevertheless valid indicators of the proportion of individuals who are skill mismatched, education mismatched or both.
} 
Table 5 Proportion of individuals in the different categories of occupational mismatch by country

\begin{tabular}{lllll}
\hline Country & Matched & Severe/mixed & $\begin{array}{l}\text { Only skill } \\
\text { mismatched }\end{array}$ & $\begin{array}{l}\text { Only education } \\
\text { mismatched }\end{array}$ \\
\hline Austria & 0.541 & 0.096 & 0.223 & 0.134 \\
Belgium & 0.511 & 0.112 & 0.252 & 0.125 \\
Cyprus & 0.471 & 0.119 & 0.223 & 0.187 \\
Czech Republic & 0.596 & 0.061 & 0.281 & 0.061 \\
Denmark & 0.486 & 0.123 & 0.205 & 0.186 \\
Estonia & 0.480 & 0.089 & 0.260 & 0.170 \\
Finland & 0.502 & 0.074 & 0.322 & 0.101 \\
France & 0.608 & 0.079 & 0.221 & 0.092 \\
Germany & 0.559 & 0.100 & 0.221 & 0.119 \\
Ireland & 0.484 & 0.127 & 0.191 & 0.198 \\
Italy & 0.587 & 0.071 & 0.174 & 0.168 \\
Netherlands & 0.504 & 0.102 & 0.281 & 0.113 \\
Poland & 0.619 & 0.039 & 0.274 & 0.069 \\
Slovak Republic & 0.578 & 0.045 & 0.317 & 0.060 \\
Spain & 0.499 & 0.116 & 0.162 & 0.223 \\
Sweden & 0.516 & 0.093 & 0.290 & 0.101 \\
United Kingdom & 0.531 & 0.078 & 0.270 & 0.121 \\
EU average & 0.586 & 0.078 & 0.203 & 0.133 \\
\hline Own & & &
\end{tabular}

Own elaboration from PIAAC data based on the selected working sample, as explained in Sect. 3. Definitions of the categories of occupational mismatch are provided in the text. All figures are weighted

mismatch, again demonstrating that an analysis should not focus on one single dimension of occupational mismatch because most of the population is mismatched on either education or skills. Thus, by considering only one dimension, we refer only to a fraction of the population. This finding is particularly relevant for policy making because it implies that policies aimed at tackling only one type of mismatch will fail to help the segment of the population that is mismatched according to the other type of mismatch.

On average, $20 \%$ of individuals are solely skill mismatched, but substantial heterogeneity exists across countries, with Ireland, Italy, and Spain exhibiting levels lower than $20 \%$ for skill mismatch and Finland and Slovakia exhibiting levels higher than $30 \%$. Individuals who are solely education mismatched compose $13 \%$ of the population on average, but again with substantial differences between countries, with levels below $10 \%$ in the Czech Republic, France, Poland, and Slovakia, and levels around or higher than $20 \%$ in Ireland and Spain. Interestingly, the countries with higher percentages in one type of mismatch have lower percentages in the other, suggesting that a negative correlation exists between the two types of mismatch. This pattern can be better visualised in Fig. 1, plotting the percentage of individuals who are solely education mismatched against the percentage of individuals who are solely skill mismatched. A clear negative relation is apparent between the two types of mismatch: a higher skill mismatch is associated with lower education mismatch (correlation of -0.78$).^{23}$

23 This relation does not exist between skill mismatch and severe/mixed mismatch, and it is weaker between education mismatch and severe/mixed mismatch. See Fig. 2 for details. 


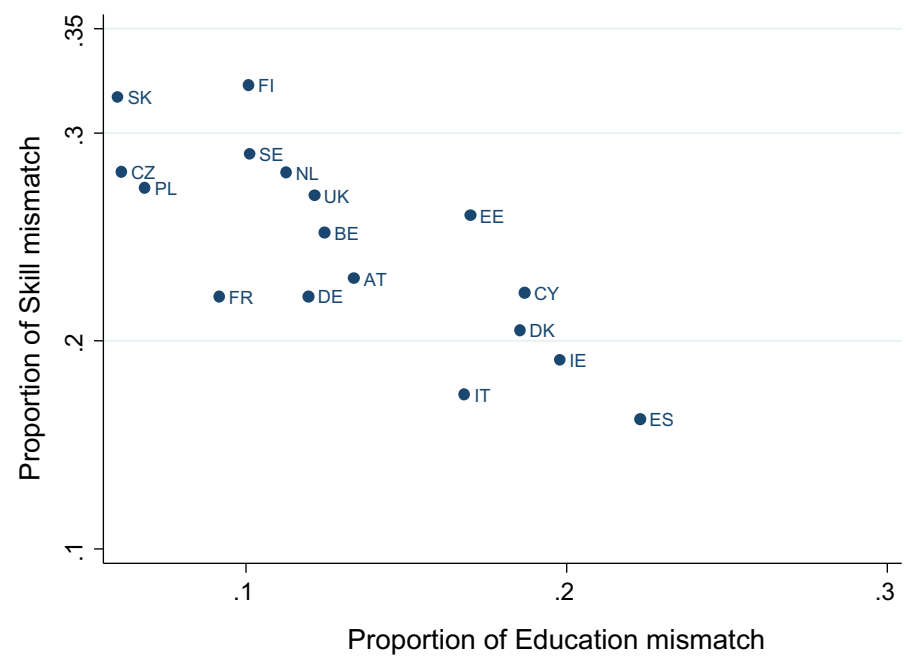

Fig. 1 Scatter plot of the proportion of individuals in a situation of skill mismatch only versus education mismatch only. Note The figure shows a scatter plot of the proportion of individuals with education mismatch only ( $x$ axis) and individuals with skill mismatch only (y axis)

In the graph, three main groups of countries can be identified. In the first group, the countries have a high level of education mismatch but a relatively low level of skill mismatch (bottom-right corner of the graph). This group consists of Italy, Spain, and Ireland. The mismatched individuals within these countries generally have a higher education level than their job requires, but their skills are at the appropriate level to perform their jobs. Thus, despite having a higher education level, they do not possess extra skills. Interestingly, the countries in this group are mostly characterised by an educational system that primarily provides general education. On the opposite upper-left corner of the graph, there is a group of countries with a high level of skill mismatch but a very low level of education mismatch. This group consists of Sweden, Finland, the Netherlands, Slovakia, the Czech Republic, and Poland. In these countries, individuals appear to have the proper education level for their jobs but possess more skills than their job requires, meaning that their skills are not fully leveraged in their work place. Interestingly, these countries are also among the top-performing countries in terms of skill outcomes, as shown by both PISA and PIAAC. In particular, we find the Scandinavian countries (Finland and Sweden) and the Netherlands in this group, which have always been among the top performers in surveys such as PISA, as well as Eastern European countries (Slovakia, the Czech Republic, and Poland), which are now catching up and appearing among the top performers in PIAAC and PISA 2012. In the final group, countries in the middle of the graph, the countries have intermediate levels of both education mismatch and skill mismatch. This group consists of Belgium, Austria, the UK, Denmark, Estonia, and Germany. Some of these countries are characterised by a long and well-established vocational education track.

The previous analysis suggests that a relationship exists between the educational system and the distribution of the different types of mismatch across countries. This finding is consistent with the existing literature reporting that the structure of educational systems plays a key role in shaping the occupational chances for students: high levels of standardisation and stratification provide better matching opportunities between supply and 
demand in the labour market (Allmendinger 1989; Shavit and Müller 1998). ${ }^{24}$ Generally, systems characterised by the presence of vocational tracks provide specific skills and clear occupational profiles, which are informative and familiar to employers, leading to better labour market chances for vocational graduates. Consequently, more stratified systems are expected to result in less overeducation than less stratified systems (Ortiz 2010). Typically, countries such as Germany, the Netherlands, Switzerland, Austria, and the Scandinavian countries are characterised by a high level of stratification, with well-established tracks of vocational education at both the secondary and tertiary levels. By contrast, southern European countries and Ireland are characterised by a low level of educational tracking and a high level of general training.

A limitation of our analysis is that we consider only the supply side of the labour market. In fact, we focus on skills and education in the labour force because PIAAC data have no information on the demand side. It could be argued that investigating the structure of the labour market in terms of employment protection legislation, economic performance, and the level of flexibility of the system could also contribute to explaining the phenomenon of occupational mismatch. For example, constraints of regional mobility, time lags between certain skill needs in the market and the time needed for individuals to acquire them, and language constraints among countries may be noted as factors that render a perfect match between demand and supply in the labour force unlikely. Moreover, the limits imposed by a high level of employment protection could impede rapid adjustments in the labour market, or the negative economic situation of a particular country might lead to higher levels of mismatch because highly qualified workers may compete with less qualified workers, thereby displacing workers in the market.

However, for the characteristics and purpose of our study, we argue that the structure of the educational system is key to appropriately interpreting the differences observed across countries in terms of occupational mismatch. In fact, as shown in Fig. 1, the clustering of countries fits a supply side explanation much better than a demand side explanation. As an example, in the group of countries with intermediate levels of both education mismatch and skill mismatch, countries characterised by very different labour market structures coexist (Germany and Austria, typically representative of the conservative-corporatist welfare state (Esping-Andersen 1990; Ferrera 1996); the UK which is characterised by a liberal welfare state regime; and Denmark, which, on the contrary, is at the other end of the continuum with a social-democratic welfare regime. Likewise, a reference to the demandside perspective seems troublesome for the countries in the upper-left corner of Fig. 1, where Scandinavian countries with highly protective social-democratic systems are close to Eastern European countries, whose welfare and labour market systems are more similar to those of a liberal regime.

Nonetheless, we believe that a demand-side approach to the issue of mismatch in the labour market may be beneficial for better understanding the different aspects of a complex phenomenon such as occupational mismatch.

Lastly, to verify whether the previous findings obscure a skewed distribution in favour of specific groups, we analysed the four types of mismatch presented in Sect. 4 by age, education level, skill level (results are available from the authors upon request). This

\footnotetext{
${ }^{24}$ Standardisation is defined as the level of homogeneity of the educational system throughout a country: a higher level of uniformity with respect to the curricula and teaching methods across the country is associated with a higher level of standardisation. Stratification is defined according to the level of internal differentiation of the system, with the level of stratification based on the number of specific tracks (for example general, academic and vocational) and the extent to which students can move from one track to other tracks.
} 
exercise aimed to elucidate whether the mismatch is driven by a particular education/skill group and whether differences exist between age groups and between countries. As expected, individuals with higher education are more likely to be in the educational and mixed mismatch groups, whereas individuals with low education are more likely to be in the matched group. Similarly, individuals with high skills are more likely to be overrepresented in the skill mismatch and mixed mismatch groups, and individuals with low skills are more likely to be overrepresented in the match group. These conclusions are not surprising given the way that education mismatch and skill mismatch are computed, but an interesting result is that no differences are found by age and country, providing support for our finding that, within different age groups and within different countries, the distribution of mismatch is quite homogeneous, with no particular age group driving the results.

\section{Conclusions}

In recent decades, concerns regarding upwards occupational mismatch in developed economies have been increasing, yet no consensus has been reached on how to conceptualise and measure this phenomenon. Education mismatch (overeducation) has been the most common way to conceptualise occupational mismatch; however, more recently, skill mismatch (overskilling) has been increasingly used owing to data availability on workers' skill levels. Although education mismatch and skill mismatch are undoubtedly related concepts, they are far from equivalent because education and skills do not have a one-toone correspondence. Nevertheless, it is unclear in the literature the extent to which these concepts and the different ways in which they are operationalised are counterparts in capturing the phenomenon of occupational mismatch.

We contribute to this discussion by using the unique opportunity provided by the recent Survey of Adult Skills (PIAAC) to compute upwards occupational mismatch indicators based on both education- (overeducation) and skill-based (overskilling) variables.

The main questions posed and the results obtained in this paper are as follows. First, what is the incidence of overeducation and overskilling in various European countries according to a comprehensive set of mismatch indicators proposed in the literature? Second, are education mismatch and skill mismatch equivalent indicators of occupational mismatch, or do they capture different phenomena? The results of our analysis show that the incidence of upward occupational mismatch greatly differs depending on its conceptualisation (overeducation and overskilling) and measurement. In fact, we find that three different phenomena seem to be captured by the indicators computed. This finding clearly suggests that the various concepts and measures of occupational mismatch are not equivalent and that the phenomena that they capture affect the population to different degrees. Accordingly, our third research question asks to what extent do overeducation and overskilling overlap at the individual level, and how does this translate into aggregate terms at country level? To answer this question, we classified individuals as having 'only education mismatch', 'only skill mismatch', and 'severe/mixed mismatch'. We find a surprisingly low percentage of individuals who are both overeducated and overskilled $(10 \%)$, while the majority of mismatched individuals exhibit only education mismatch $(13 \%)$ or only skill mismatch $(20 \%)$. An analysis of occupational mismatch focusing on only one dimension of occupational mismatch is likely to neglect a significant part of the mismatched population. Finally, we analyse differences between countries aggregating individuals' information. We find a strong negative correlation between 'only education' 
and 'only skill' mismatch across countries and identify three main groups of countries with specific patterns of occupational mismatch. The first group consists of Italy, Spain, Ireland, and presents high levels of overeducation but relatively low levels of overskilling. These countries are characterised by a low level of educational tracking and a high level of general training. Thus, policy in these countries may try to align the educational system with the needs of the labour market by modernising the curricula and teaching methods in the educational system and by providing more specific knowledge. By contrast, countries in the second group, comprising Scandinavian and some Eastern European countries, are characterised by high levels of overskilling and low levels of overeducation. These countries are also among the top-performing countries in terms of both educational outcomes provided by the PISA survey and skills outcomes provided by PIAAC. Thus, current top performing countries have the potential to improve their relative positions by benefitting from the reservoir of skills possessed by their working-age population.

In conclusion, regardless of the examined dimension (i.e., education mismatch or skill mismatch), occupational mismatch always highlights some inefficiency of a country's educational system and labour market. In the case of education mismatch, the workers acquire knowledge that is not subsequently transferred into skills that are needed for a certain job. In the case of skill mismatch, workers possess a reservoir of skills that can be further exploited. More interestingly, the distribution of mismatch seems to reflect a 'multispeed' Europe. Specifically, Scandinavian countries, which are typically the best-performing countries in several domains (education, economics, welfare), and some "catching up' Eastern European countries (with good performance in PIAAC and/or PISA) are also the countries that are affected by a 'positive' mismatch: they are endowed with a reservoir of high-skilled workers, which potentially can even further improve their performance. By contrast, education mismatch, which has negative effects on both the individual and the macro level (e.g., lower productivity, psychological stress), mostly affects countries that are already low educational and economic performers (e.g., Spain, Italy, Ireland). This result suggests that these lower-performing EU member states might benefit from policy aiming to redesign their educational systems in order to ensure high levels of skills and render their economies more competitive in the medium to long run.

Acknowledgments This article builds on previous work carried out for the JRC's Centre for Research on Education and Lifelong Learning (CRELL), in the framework of the project KNOW (Human Capital for Prosperity and Sustainable Growth in Europe). The authors would like to specially thank Dorota Maria Weziak-Bialowolska for her useful contributions. The views expressed are purely those of the writers and may not in any circumstances be regarded as stating an official position of the European Commission.

Open Access This article is distributed under the terms of the Creative Commons Attribution 4.0 International License (http://creativecommons.org/licenses/by/4.0/), which permits unrestricted use, distribution, and reproduction in any medium, provided you give appropriate credit to the original author(s) and the source, provide a link to the Creative Commons license, and indicate if changes were made.

\section{Appendix 1: Principal Component Analysis}

In this annex, we provide the necessary technical details related to the Principal Component Analysis performed. See Sect. 3.2 for the interpretation of the results and how they are used to proceed with the research question of the paper.

Given the binary nature of the mismatch variables, we use polychoric correlations to construct the covariance matrix from which the eigenvalues and eigenvectors are calculated. To choose the number of components retained, we apply the Kaiser criterion, 


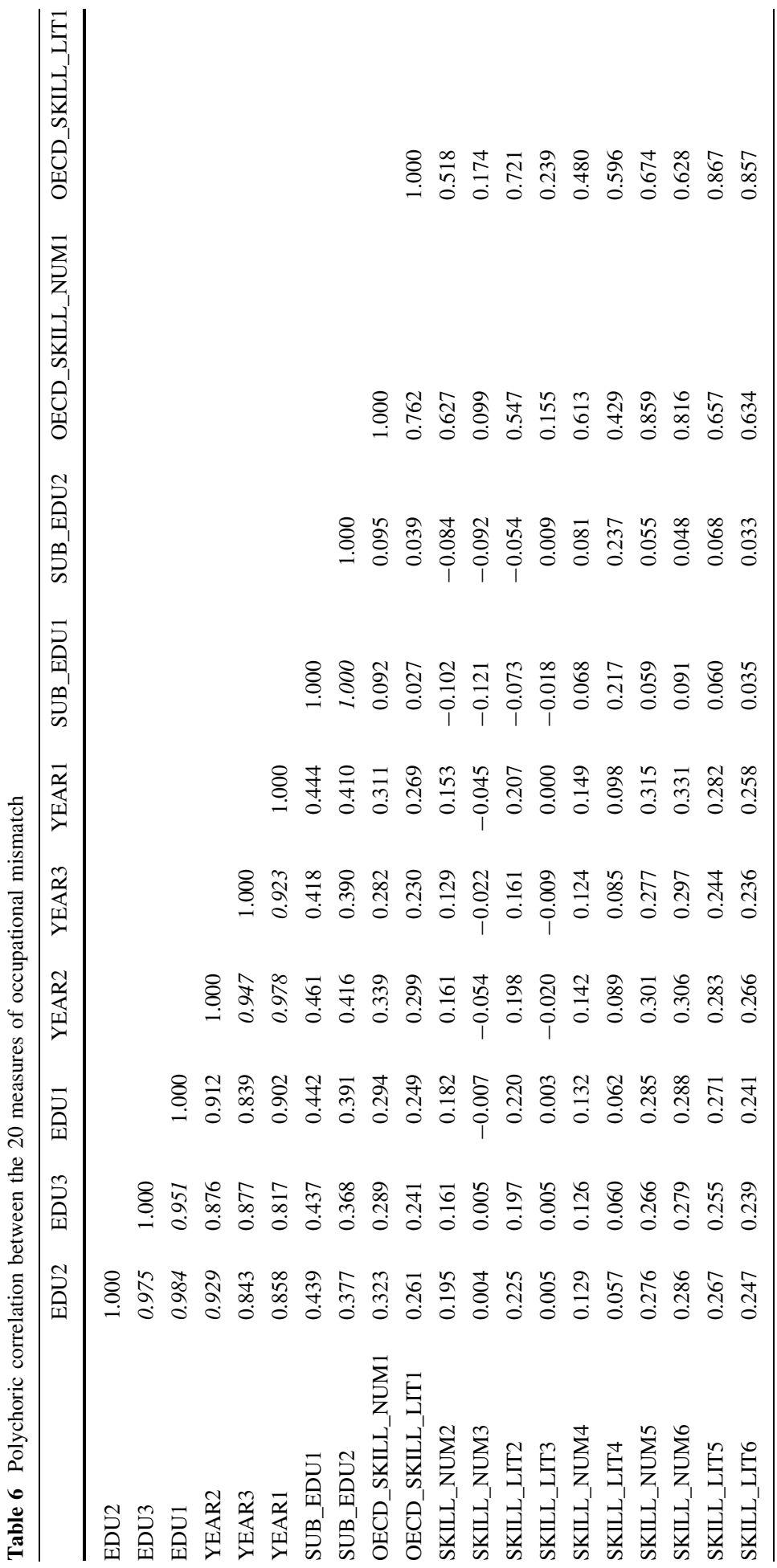




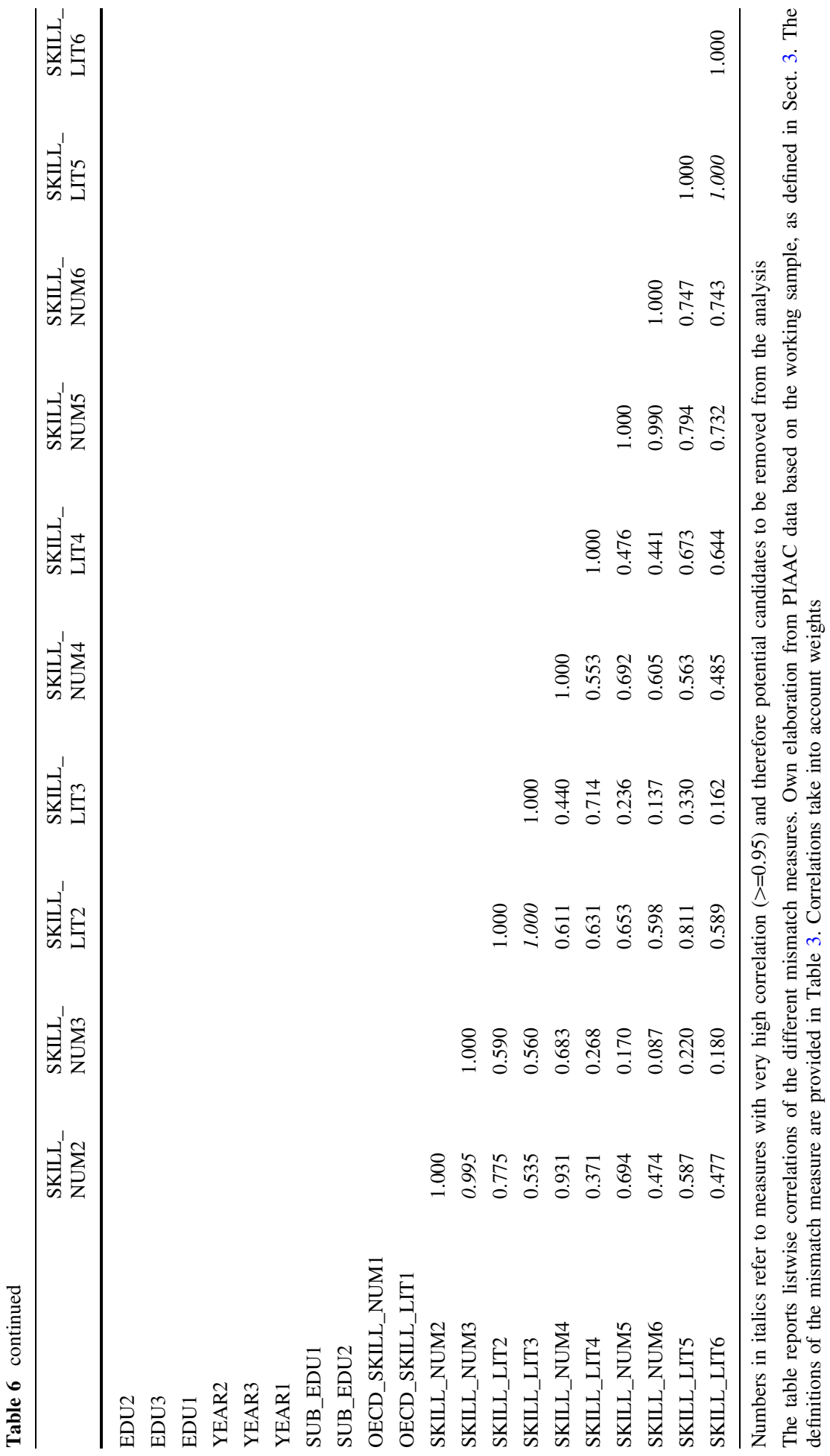




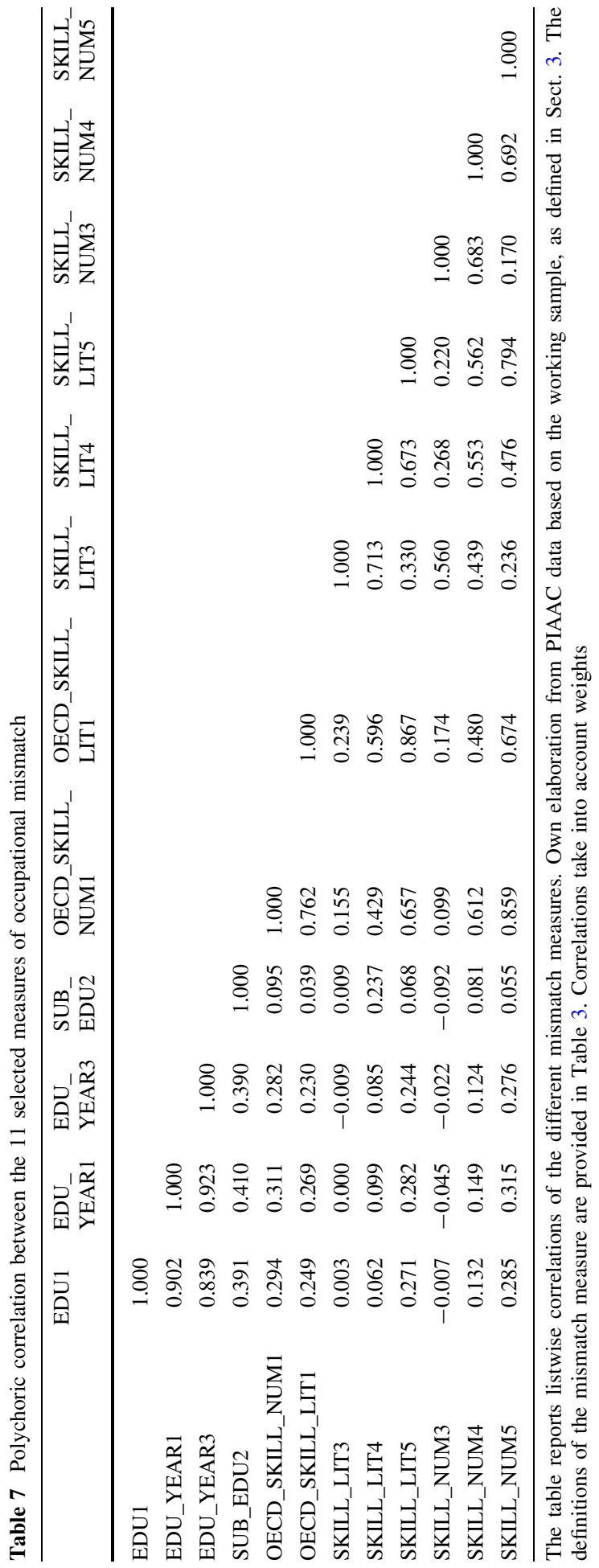


Table 8 Factor loadings from the PCA for the occupational mismatch analysis

Numbers in bolditalics refer to the measures that can interchangeably go into Factor 1 or Factor 3, namely:

SKILL_LIT4 and SKILL_NUM4

Numbers in bold refer to the measures included in each factor

The table reports the rotated factor loadings emerging from the PCA

Own elaboration from PIAAC data based on the working sample, as defined in Sect. 3

\begin{tabular}{lccc}
\hline & FACTOR 1 & FACTOR 2 & FACTOR 3 \\
\hline EDU1 & 0.153 & $\mathbf{0 . 9 2 0}$ & -0.012 \\
EDU_YEAR1 & 0.179 & $\mathbf{0 . 9 4 7}$ & -0.024 \\
EDU_YEAR3 & 0.139 & $\mathbf{0 . 9 2 8}$ & -0.015 \\
SUB_EDU2 & -0.056 & $\mathbf{0 . 5 9 1}$ & 0.119 \\
OECD_SKILL_NUM1 & $\mathbf{0 . 8 9 1}$ & 0.178 & 0.032 \\
OECD_SKILL_LIT1 & $\mathbf{0 . 8 8 2}$ & 0.118 & 0.124 \\
SKILL_LIT3 & 0.142 & -0.026 & $\mathbf{0 . 8 6 5}$ \\
SKILL_LIT4 & $\mathbf{0 . 5 3 5}$ & 0.048 & $\mathbf{0 . 6 1 7}$ \\
SKILL_LIT5 & $\mathbf{0 . 8 6 9}$ & 0.142 & 0.236 \\
SKILL_NUM3 & 0.058 & -0.059 & $\mathbf{0 . 8 3 2}$ \\
SKILL_NUM4 & $\mathbf{0 . 5 7 8}$ & 0.061 & $\mathbf{0 . 6 2 9}$ \\
SKILL_NUM5 & $\mathbf{0 . 8 9 3}$ & 0.167 & 0.134 \\
\hline
\end{tabular}

selecting a number of components equal to the number of eigenvalues greater than 1 . Finally, to facilitate the interpretation of the extracted components, we rely on orthogonal rotation using the varimax approach.

The polychoric correlation (Table 6) matrix reveals that some measures have very high correlations (close to 1 for some variables and greater than 0.90 for others); therefore, before implementing the PCA, we account for the correlations between measures and drop some of them. As a first step, we exclude one of the variables within the pairs showing correlations equal or close to one, namely, SUB_EDU1, SKILL_NUM2, SKILL_LIT2, SKILL_NUM6, and SKILL_LIT6. ${ }^{25}$ After dropping these variables, we still identify some problems in the calculation of the factor loadings owing to negative eigenvalues. Therefore, we decide to also exclude EDU2, EDU3, and EDU_YEAR2 because of their very high correlations with EDU1, EDU_YEAR1, and EDU_YEAR3, respectively. ${ }^{26}$ The new correlation matrix for the remaining 12 measures is presented in Table 7, and we use this correlation matrix to calculate the eigenvalues and the eigenvector for the PCA. ${ }^{27}$ With this matrix, the PCA is computed correctly, and no errors arise in the computation of eigenvalues and eigenvectors.

Note that, as shown by the factor loadings in Table 8, although all other indicators present strong correlations with only one component, the indicators SKILL_LIT4 and

\footnotetext{
$\overline{25}$ We attempt to exclude other variables (e.g., SKILL_NUM6NUM5 rather than SKILL_NUM5NUM6), but the final results of the PCA do not change.

${ }^{26}$ We also attempt to exclude EDU_YEAR3 because of its correlation with EDU_YEAR1 that is higher than 0.90 , but the results are the same as those obtained when we include this variable.

27 Tables 6 and 7 use listwise correlation. If we include all 12 measures, we consider about 40,000 of the 55,000 individuals because some of the measures are missing for part of our working sample. In particular, the variables EDU_YEAR1 and EDU_YEAR3 are missing for Germany, as shown in Table 3; thus, this analysis excludes Germany. As a robustness check, we run the PCA while dropping these two variables to include German individuals; the results are the same. In particular, the variables related to education, EDU1 and SUB_EDU2 are grouped because they are correlated mainly to one component, and the skill variables are grouped because they are correlated to the two aforementioned components. In addition, the measures that are missing for most of the individuals are the groups built by using the OECD's definition; thus, we replicate the analyses by excluding these two measures, which increases the sample size to 49,000, and we find that the same three components are extracted. Finally, we produce correlation matrices and run the PCA using pairwise correlation instead of the listwise one, and the results are confirmed.
} 
SKILL_NUM4 appear to be correlated with two different components, namely, 2 and 3. In fact, these two indicators of skill mismatch are built by relying on both the distribution of skills in the population and the use of skills at work; therefore, they are a combination of the two broad types of skill mismatch indicators that we identify from the PCA. This result is confirmed using both oblique and orthogonal rotations.

\section{Appendix 2: Further Figures}

See Fig. 2.

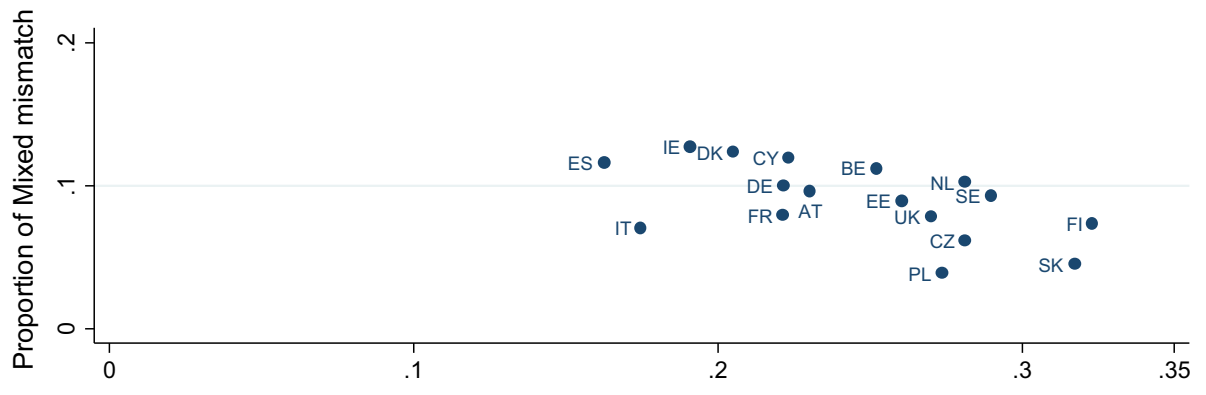

Proportion of Skill mismatch

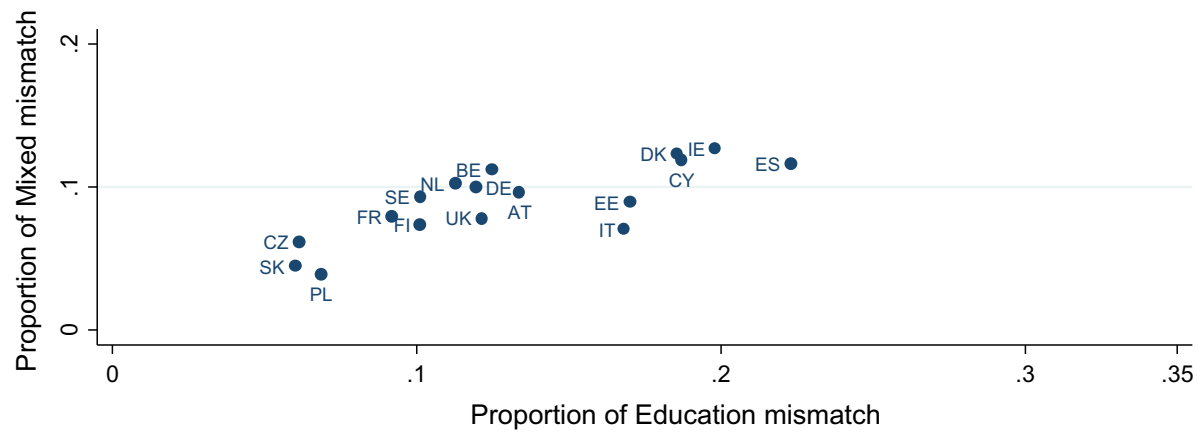

Fig. 2 Scatter plot of the proportion of individuals with severe/mixed mismatch versus individuals with skill or education mismatch only

\section{References}

Allen, J., \& De Weert, E. (2007). What do education mismatches tell us about skill mismatches? A crosscountry analysis. European Journal of Education, 42(1), 59-73. doi:10.1111/j.1465-3435.2007.00283. $\mathrm{x}$.

Allen, J., \& van der Velden, R. (2001). Education mismatches versus Skill Mismatches: Effects on wages, job satisfaction, and on-the-job search. Oxford Economic Papers, 53(3), 434-452.

Allen, J., van der Velden, R., \& Levels, M. (2013). Skill mismatch and use in developed countries: Evidence from the PIAAC Study. RM/13/061. Maastricht University, School of Business and Economics. 
Allmendinger, J. (1989). Educational systems and labor market outcomes. European Sociological Review, 5(3), 231-250.

Baert, S., Cockx, B., \& Verhaest, D. (2013). Overeducation at the start of the career: Stepping stone or trap? Labour Economics 25 (December). European Association of Labour Economists 24th Annual Conference, Bonn, Germany, 20-22 September 2012: 123-40. doi:10.1016/j.labeco.2013.04.013.

Battu, H., Belfield, C. R., \& Sloane, P. J. (2000). How well can we measure graduate over-education and its effects? National Institute Economic Review, 171(1), 82-93. doi:10.1177/002795010017100107.

Bauer, T. K. (2002). Education mismatch and wages: A panel analysis. Economics of Education Review, 21(3), 221-229. doi:10.1016/S0272-7757(01)00004-8.

Becker, G. S. (1976). Human Capital. New York: National Bureau of Economic Research.

Brynin, M. (2002). Overqualification in employment. Work, Employment \& Society, 16(4), 637-654. doi:10. 1177/095001702321587406.

Cedefop. (2010). The skill matching challenge: Analysing skill mismatch and policy implications. Luxembourg: Publications Office of the European Union.

Chevalier, A. (2003). Measuring over-education. Economica, 70(279), 509-531. doi:10.1111/1468-0335. t01-1-00296.

Chevalier, A., \& Lindley, J. (2009). Overeducation and the skills of UK graduates. Journal of the Royal Statistical Society: Series A (Statistics in Society), 172(2), 307-337. doi:10.1111/j.1467-985X.2008. 00578.x.

Desjardins, R., \& Rubenson, K. (2011). An analysis of skill mismatch using direct measures of skills. OECD Education Working Papers. Paris: Organisation for Economic Co-operation and Development. http:// www.oecd-ilibrary.org/content/workingpaper/5kg3nh9h52g5-en.

Dolado, J. J., García-Serrano, C., \& Jimeno, J. F. (2002). Drawing lessons from the boom of temporary jobs in Spain. The Economic Journal, 112(480), F270-F295.

Dorn, D., \& Sousa-Poza, A. (2005). Overqualification: Permanent or transitory?. Gallen: University of St.

Duncan, G. J., \& Hoffman, S. D. (1981). The incidence and wage effects of overeducation. Economics of Education Review, 1(1), 75-86.

Elias, P., \& Purcell, K. (2004). Is mass higher education working? Evidence from the labour market experiences of recent graduates. National Institute Economic Review, 190(1), 60-74. doi:10.1177/ 002795010419000107

Esping-Andersen, G. (1990). The three worlds of welfare capitalism. Princeton, N.J.: Princeton University Press.

Ferrera, M. (1996). The "Southern Model" of welfare in social Europe. Journal of European Social Policy, 6(1), 17-37. doi:10.1177/095892879600600102.

Freeman, R. B. (1976). The over-educated American. New York: Academic Press.

Frei, C., \& Sousa-Poza, A. (2012). Overqualification: Permanent or transitory? Applied Economics, 44(14), 1837-1847. doi:10.1080/00036846.2011.554380.

Green, F., \& McIntosh, S. (2007). Is there a genuine under-utilization of skills amongst the over-qualified? Applied Economics, 39(4), 427-439.

Green, F., \& Zhu, Y. (2010). Overqualification, job dissatisfaction, and increasing dispersion in the returns to graduate education. Oxford Economic Papers, 62(4), 740-763. doi:10.1093/oep/gpq002.

Groeneveld, S. M. (1997). Passend Meten, over definities en metingen van overscholing. Tijdschrift Voor Arbeidsvraagstukken, 13, 273-282.

Groot, W., \& van den Brink, H. M. (2000). Overeducation in the labor market: A meta-analysis. Economics of Education Review, 19(2), 149-158. doi:10.1016/S0272-7757(99)00057-6.

Halaby, C. N. (1994). Overeducation and skill mismatch. Sociology of Education, 67(1), 47-59. doi:10. $2307 / 2112749$.

Hartog, J. (2000). Over-education and earnings: Where are we, where should we go? Economics of Education Review, 19, 131-147.

Hartog, J., \& Oosterbeek, H. (1988). Education, allocation and earnings in the Netherlands: Overschooling? Economics of Education Review, 7(2), 185-194.

Kiker, B. F., Santos, M. C., \& Mendes De Oliveira, M. (1997). Overeducation and undereducation: Evidence for Portugal. Economics of Education Review, 16(2), 111-125.

Krahn, H., \& Lowe, G. S. (1998). Literacy utilization in Canadian workplaces. Ottawa and Hull: Statistics Canada and Human Resource Development Canada.

Leuven, E., \& Oosterbeek, H. (2011). Overeducation and mismatch in the labor market. IZA DP No. 5523. Discussion Paper Series. Institute for the Study of Labor (IZA).

Mavromaras, K. G., McGuinness, S., \& Fok, Y. K. (2007a). Assessing the incidence and wage effects of over-skilling in the Australian labour market. IZA Discussion Paper 2837. Institute for the Study of Labor (IZA). http://ideas.repec.org/p/iza/izadps/dp2837.html. 
Mavromaras, K., McGuinness, S., \& Wooden, M. (2007b). Overskilling in the Australian labour market. Australian Economic Review, 40(3), 307-312. doi:10.1111/j.1467-8462.2007.00468.x.

McGoldrick, K., \& Robst, J. (1996). Gender differences in overeducation: A test of the theory of differential overqualification. American Economic Review, 86(2), 280-284.

McGuinness, S. (2006). Overeducation in the labour market. Journal of Economic Surveys, 20(3), 387-418. doi:10.1111/j.0950-0804.2006.00284.x.

Mendes de Oliveira, M., Santos, M. C., \& Kiker, B. F. (2000). The role of human capital and technological change in overeducation. Economics of Education Review, 19, 199-206.

Nauze-Fichet, E., \& Tomasini, M. (2002). Diplôme et Insertion Sur Le Marché Du Travail: Approches Socioprofessionnelle et Salariale Du Déclassement. Economie et Statistique, 354, 21-48.

OECD. (2013). OECD skills outlook 2013: First results from the survey of adult skills. doi: 10.1787/ 9789264204256-en.

Oosterbeek, H. (2000). Introduction to special issue on overschooling. Economics of Education Review, 19(2), 129-130. doi:10.1016/S0272-7757(99)00040-0.

Ortiz, L. (2010). Not the right job, but a secure one over-education and temporary employment in France, Italy and Spain. Work, Employment and Society, 24(1), 47-64. doi:10.1177/0950017009353657.

Pellizzari, M., \& Fichen, A. (2013). A new measure of skills mismatch. OECD Social, Employment and Migration Working Papers. Paris: Organisation for Economic Co-operation and Development. http:// www.oecd-ilibrary.org/content/workingpaper/5k3tpt04lcnt-en.

Quinn, M. A., \& Rubb, S. (2006). Mexico's Labor Market: The importance of education-occupation matching on wages and productivity in developing countries. Economics of Education Review, 25(2), $147-156$.

Quintini, G. (2011). Over-qualified or under-skilled. OECD Social, Employment and Migration Working Papers. Paris: Organisation for Economic Co-operation and Development. http://www.oecd-ilibrary. org/content/workingpaper/5kg58j9d7b6d-en.

Rubb, S. (2013). Overeducation, undereducation and asymmetric information in occupational mobility. Applied Economics, 45(6), 741-751.

Rumberger, R. W. (1987). The impact of surplus schooling on productivity and earnings. The Journal of Human Resources, 22(1), 24. doi:10.2307/145865.

Shavit, Y. \& Müller, W. (Eds.), (1998). From School to Work: A comparative study of educational qualifications and occupational destinations. Oxford: Clarendon Press.

Sicherman, N. (1991). "Overeducation" in the labor market. Journal of Labor Economics, 9(2), 101-122.

Sloane, P. J., Battu, H., \& Seaman, P. T. (1999). Overeducation, undereducation and the British labour market. Applied Economics, 31(11), 1437-1453. doi:10.1080/000368499323319.

Tsang, M. C., \& Levin, H. M. (1985). The economics of overeducation. Economics of Education Review, 4(2), 93-104.

Verdugo, R. R., \& Verdugo, N. T. (1989). The impact of surplus schooling on earnings: Some additional findings. The Journal of Human Resources, 24(4), 629. doi:10.2307/145998.

Verhaest, D., \& Omey, E. (2006). The impact of overeducation and its measurement. Social Indicators Research, 77(3), 419-448. doi:10.1007/s11205-005-4276-6.

Vieira, J., \& Cabral, A. (2005). Skill mismatches and job satisfaction. Economics Letters, 89(1), 39-47. 